\title{
Hydrophilic Fluorescent Nanoprodrug of Paclitaxel for Glioblastoma Chemotherapy
}

\author{
Jonathan Daniel, ${ }^{\dagger}$ Maeva Montaleytang, ${ }^{\ddagger},, \|$ Sounderya Nagarajan, ${ }^{\ddagger}, \| \odot$ Sébastien Picard, ${ }^{\dagger}$ \\ Guillaume Clermont, $^{\dagger}$ Adina N. Lazar, ${ }^{\dagger}$ Noé Dumas, ${ }^{\ddagger} \odot$ Florian Correard, ${ }^{\ddagger},{ }^{\ddagger}$ Diane Braguer, \\ Mireille Blanchard-Desce, ${ }^{*}, \oplus$ Marie-Anne Estève, ${ }^{*}, \sharp,{ }^{\ddagger}$ and Michel Vaultier ${ }^{\dagger}$
}

†Univ. Bordeaux, Institut des Sciences Moléculaires (CNRS UMR 5255), Bâtiment A12, 351 Cours de la Libération, 33405 Talence Cedex, France

${ }^{\ddagger}$ Aix Marseille Univ, CNRS, INP, Inst Neurophysiopathol, Faculté de Pharmacie, 27 Boulevard Jean Moulin - CS 30064 , 13385 Marseille Cedex 05, Marseille, France

${ }^{\S}$ AP-HM, Hôpital Timone, 264 Rue Saint Pierre, 13385 Marseille Cedex 05, France

\section{Supporting Information}

\begin{abstract}
Highly water-soluble, nontoxic organic nanoparticles on which paclitaxel (PTX), a hydrophobic anticancer drug, has been covalently bound via an ester linkage ( $4.5 \%$ of total weight) have been prepared for the treatment of glioblastoma. These soft fluorescent organic nanoparticles (FONPs), obtained from citric acid and diethylenetriamine by microwave-assisted condensation, show suitable size $(\varnothing=17-$ $30 \mathrm{~nm}$ ), remarkable solubility in water, softness as well as strong blue fluorescence in an aqueous environment that are fully retained in cell culture medium. Moreover, these FONPs were demonstrated to show in vitro safety and preferential internalization in glioblastoma cells through caveolin/lipid raft-mediated endocytosis. The PTX-conjugated FONPs retain excellent solubility in water and remain stable in water (no leaching), while they showed anticancer activity against glioblastoma cells in two-dimensional and three-dimensional culture. PTX-specific effects on microtubules reveal that PTX is intracellularly released from the nanocarriers in its active form, in relation with an intracellular-promoted lysis of the ester linkage. As such, these hydrophilic prodrug formulations hold major promise as biocompatible nanotools for drug delivery.
\end{abstract}

\section{INTRODUCTION}

Vectorization of anticancer agents is a recent therapeutic strategy to improve their targeting and delivery. It is an important field of research to overcome disadvantages inherent to the low cancer cell targeting of conventional chemotherapy, unfavorable pharmacokinetic drug profile, low aqueous solubility, and severe systemic toxicity. ${ }^{1,2}$ In this context, several kinds of nanoparticles (e.g., polymeric nanoparticles, liposomes, solid lipid nanoparticles, and so forth) have been explored in recent years as nanocarriers for anticancer drugs (chemical agents, peptides, antibodies...). ${ }^{2-4}$ Nowadays, two main strategies to improve the pharmacokinetic profile of anticancer drugs using nanoparticles are used: the encapsulation of the drug in the nanoparticles or its covalent bonding, leading to a prodrug. In the first case, a spontaneous drug diffusion called burst release is often observed, resulting in adverse events in clinical use. ${ }^{5}$ Conversely, the covalent strategy may solve the drug burst release problem and offers a delayed effect. $^{6-9}$ Indeed, covalent nanoprodrugs show a higher stability with lower drug clearance than encapsulated drugs $^{5}$ and a smaller batch-to-batch variation than free drug- loaded liposomes, micelles, biodegradable polymers, and hydrogels. $^{10}$

Paclitaxel (PTX), which belongs to the family of microtubule-targeting agents, is one of the most useful and effective antineoplastic drugs for the treatment of many solid cancers and their metastasis. ${ }^{11}$ However, because of its poor water solubility (less than $0.01 \mathrm{mg} / \mathrm{mL}$ ), PTX is commonly formulated with Cremophor EL (polyoxyethylated castor oil) or other cosolvents before being administered, resulting in dose-limiting toxicity and hypersensitivity in some patients. ${ }^{12}$ In addition, PTX is a substrate of P-glycoprotein, an efflux pump responsible for the acquisition of multidrug resistance of cancer cells ${ }^{13}$ and able to prevent PTX crossing of the bloodbrain barrier (BBB). ${ }^{14}$ Thus, PTX is often considered as a model for any delivery system, and a variety of PTX formulations have been developed, which generally allow an increase of the maximum tolerated dose of PTX with a

Received: August 12, 2019

Accepted: October 10, 2019

Published: October 24, 2019 


\section{Scheme 1. Synthesis Steps of the FONP-PTX Prodrug ${ }^{a}$}

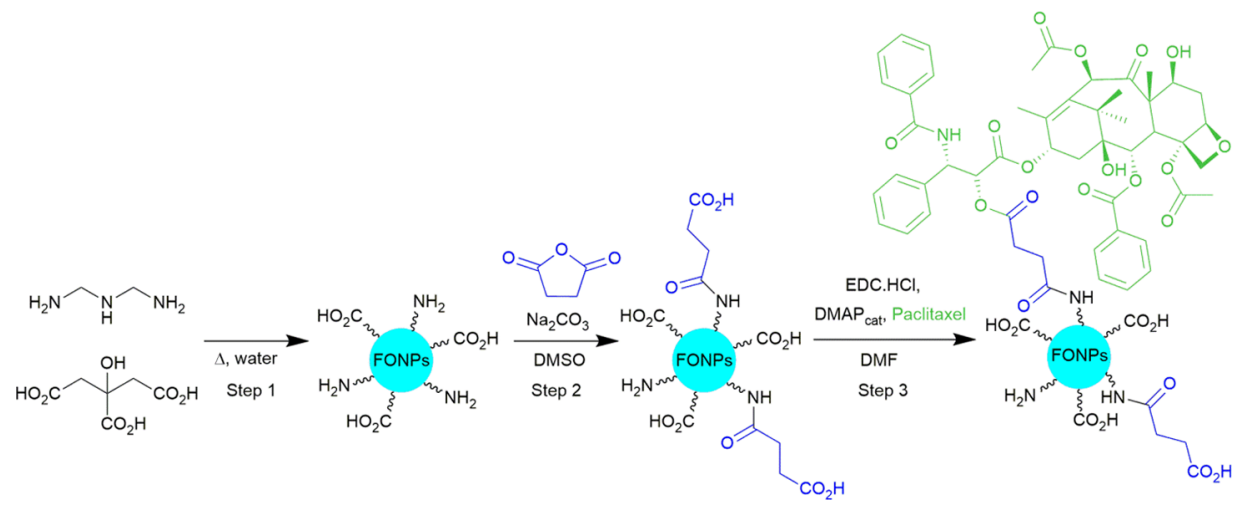

${ }^{a_{\text {Step }}}$ 1: Synthesis of FONP platforms. Citric acid, diethylenetriamine, water, microwave $(600 \mathrm{~W}), 2$ min; step 2: Activation of FONP platforms. Succinic anhydride, $\mathrm{Na}_{2} \mathrm{CO}_{3}$, DMSO, rt, 2 h; step 3: Grafting of PTX. EDC.HCl, DMAP, PTX, DMF, rt, $60 \mathrm{~h}$.

decrease of adverse effects. Since the approval of Abraxane, the albumin-bound PTX, that has shown clinical efficacy without the side effects associated with Cremophor EL, many innovative PTX formulations are still undergoing preclinical and clinical trials. ${ }^{10,15}$

However, few of these formulations have been developed for the treatment of malignant brain tumors (primary brain tumors or metastases of solid tumors), although they display a high mortality rate. The presence of the BBB that protects the brain from foreign elements complicates tumor drug delivery. ${ }^{16}$ Among primary brain tumors, glioblastoma is characterized by an aggressive growth and a highly invasive behavior. Current standard therapy consists of maximal safe surgery following concomitant radiochemotherapy. Despite such a regimen, the median survival period is only 15 months because of unavoidable recurrences. ${ }^{17}$ In that context, novel therapeutic approaches are required, and nanoparticles covalently bound to PTX, which would release PTX preferentially when internalized in cancer cells, could offer a perspective to use PTX in brain tumor treatment. ${ }^{16,18,19}$ PTX poliglumex (PTX bound to poly-L-glutamic acid) has reached clinical trials in glioblastoma but induced substantial myelosuppression (grade 4 hematologic toxicity) in combination with temozolomide and concurrent radiation ${ }^{20}$ and failed to demonstrate an improvement of progression free survival or overall survival when used as a single agent in combination with radiation therapy as compared to temozolomide with radiation therapy. ${ }^{21}$ Other prodrugs of PTX have been the subject of preclinical studies. PTX conjugated to linoleic acid (CLA-PTX) has demonstrated promising results as it showed cytotoxicity and higher cellular uptake efficiency in C6 glioma cells in vitro and antitumor efficacy in brain tumor-bearing rats. ${ }^{22}$ Yet, it is poorly soluble in water, thus requiring the preparation of a microemulsion containing Cremophor EL among other excipients. ${ }^{23}$ The solubility in water of other PTX nanoprodrugs which have been assayed in vitro or in vivo against glioma was not determined. This questions their utilization without the use of Cremophor EL, which represents a major shortcoming for clinical use. $^{24-26}$

In this context, we have prepared soft fluorescent organic nanoparticles (FONPs) which combine remarkable solubility and bright blue fluorescence properties in aqueous media and which present a high number of surface groups for further conjugation of hydrophobic drugs such as PTX. More specifically, we have synthesized intrinsically FONPs which are highly water-soluble, nontoxic, and internalized preferentially in glioblastoma cells. A subsequent efficient two-step (chemical activation, followed by covalent functionalization) optimized protocol leads to PTX-conjugated FONPs, where PTX is bound to the nanoparticles via an ester linkage which masks the biological activity of PTX. FONPs-PTX retain excellent solubility in water and stability of the bond in biological conditions, thus potentially decreasing side effects.

\section{RESULTS AND DISCUSSION}

Synthesis of Soft Nanoparticles. FONPs are prepared via a bottom-up synthesis by condensation of a mixture of citric acid and diethylenetriamine (DETA). This is reminiscent to the preparation of carbon dots (CDs) from basic polyamine and carboxylic acid molecules by the microwave-assisted hydrothermal process. ${ }^{27,28}$ The experimental protocol involves flash heating of a mixture of citric acid and DETA using microwave activation (Scheme 1, step 1). This simple and easily scalable procedure leads to a brownish solid material that contains both FONPs and residual oligomers/small polymers which can be removed by washing with ethanol. The FONPs possess numerous chemically accessible carboxylic acids and amine functions (ca. 1000 amines per nanoparticle). These amino surface groups ensure the water solubility of the nanoparticles (i.e., over $250 \mathrm{~g} / \mathrm{L}$ ), while the carboxylic acids are of major interest for further functionalization and grafting of an hydrophobic drug via an intracellular-cleavable ester linkage.

Characterization of the Nanoparticles and Optical Properties. Despite numerous advantages of the synthesis of such nanoparticles by the microwave-assisted hydrothermal process, the nature of fluorescence emitters has been the subject of much debate. ${ }^{29-33}$ In the case of FONPs prepared from citric acid and $\alpha, \beta$-diamino derivatives, the bright fluorescence was attributed to the formation during the hydrothermal process of pyridone derivatives caged in a complex polymeric matrix..$^{27,34-37}$ It should be stressed that a precise control of the experimental conditions is crucial to guarantee the reproducibility of the nature, properties, and characteristics of the obtained nanoparticles. In particular, slight changes and harsher experimental conditions induce carbonization processes (i.e., formation of graphitic- or graphene-like domains $)^{27,38,39}$ and lead to so-called fluorescent CDs or CDs. These CDs are sometimes also named quantum CDs (QCDs) in relation with their small size $(<10 \mathrm{~nm})$. The 


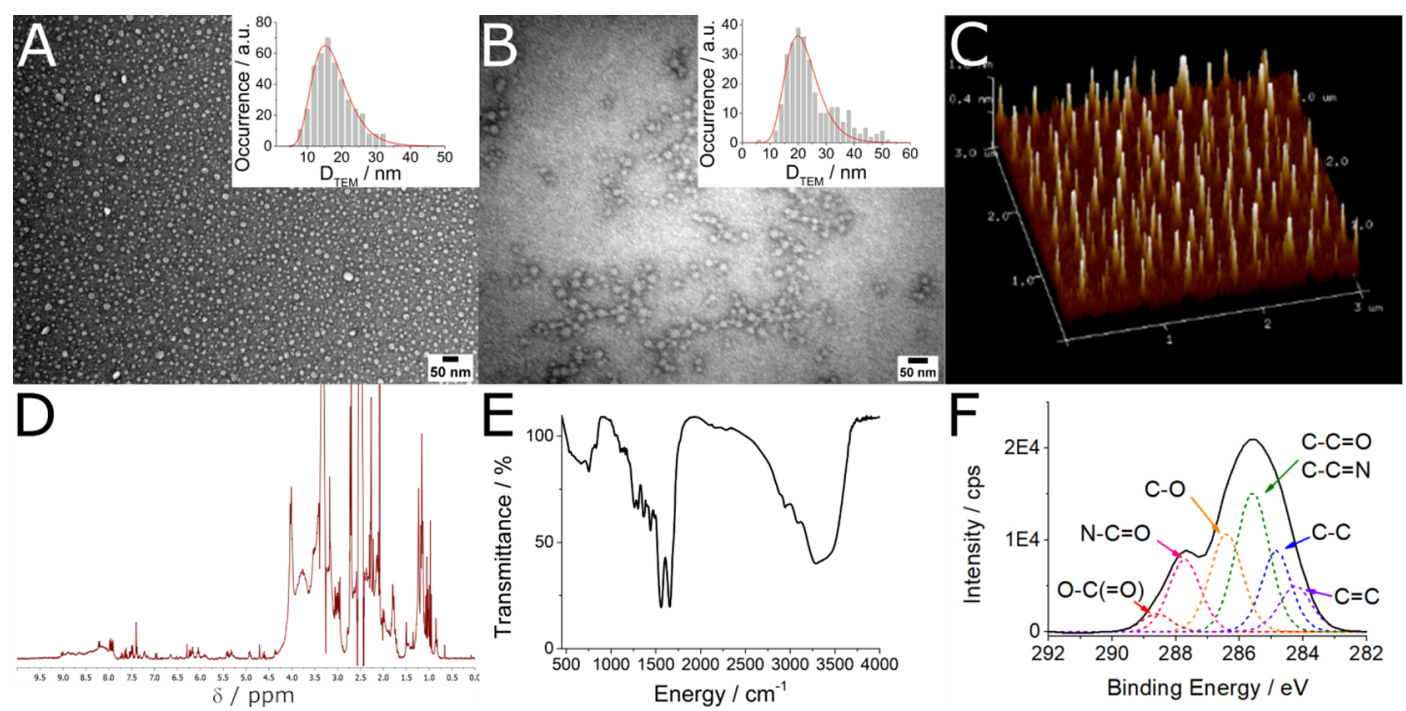

Figure 1. (A) TEM images of FONPs with size distribution fitted with a log normal in caption; (B) TEM images of FONPs-PTX with size distribution fitted with a log normal in caption; (C) AFM images of FONPs; (D) ${ }^{1} \mathrm{H}$ NMR spectrum in DMSO- $d_{6}$ of FONPs-PTX; (E) IR spectrum of FONPs; and (F) carbon XPS spectrum of FONPs.

fluorescent CDs-although having the same denomination in the literature-encompass a wide range of nanoparticles. This fuzzy denomination generates major misperception, in particular with respect to the origin of their fluorescence properties. The so-called CDs can be prepared from diverse starting materials using varying experimental conditions. $^{27,29,33,40,41}$ A crucial issue is then the varying (and sometimes undefined) degree of carbonization. In many cases when carbonization actually occurs, the luminescence of the CDs is attributed to the presence of graphene sheets (or "carbogenic" centers or domains) within the nanoparticles. Such luminescence is characterized by excitation-dependent emission and often results in lower fluorescence quantum yields, unless passivation of the surface is realized.

Having this in mind, we thoroughly investigated the properties and chemical composition of our FONPs using complementary techniques ranging from material science to spectroscopy. It is well known that the carbonization process is strongly influenced by temperature and that the experimental conditions of the hydrothermal process are critical in terms of ensuing optical properties. ${ }^{39}$ Indeed, temperatures above 200 ${ }^{\circ} \mathrm{C}$ lead to the formation of smaller nanoparticles $(\ll 10 \mathrm{~nm})$ containing graphitic carbon domains. These carbon dots (CDs or QCDs) show excitation-dependent luminescence (reminiscent of quantum confinement) and smaller fluorescence quantum yields. In contrast, lower temperatures (typically below $180{ }^{\circ} \mathrm{C}$ ) lead to strongly fluorescent nanoparticles in water, which result from multiple condensation and dehydration reactions. We chose to use these gentle hydrothermal conditions to avoid the carbonization process. As shown in Figures $1 \mathrm{~A}-\mathrm{C}$ and $\mathrm{S} 1$, transmission electron microscopy (TEM) and atomic force microscopy (AFM) conducted on our FONPs evidenced the presence of small nanoparticles with a dry diameter in the range of $10-30 \mathrm{~nm}$ (TEM and AFM) and a typical height of $2.2 \mathrm{~nm}$ (AFM). The difference between the diameter and height suggests that these nanoparticles are soft enough to flatten when dry, yielding pancake-shaped nanoparticles. Thanks to AFM, we measured the Young modulus of the nanoparticles and found values in the range 1-4 GPa which are typical of polymer derivatives.
The slightly negative surface potential of our nanoparticles $(\zeta$ $=-7 \mathrm{mV}$ ) suggests a slight excess of carboxylic acid groups compared to primary or secondary amines at their surface. Elemental analysis data (Table S1) evidence that the carbonization of the citric acid and diethylene triamine mixture remains low. Indeed, the FONPs were found to contain a significant amount of nitrogen and oxygen (17 and 29\%, respectively) as well as hydrogen (7\%). These data indicate that they are close to organic nanomaterials (i.e., polymer dots).

${ }^{1} \mathrm{H}$ NMR experiments in $\mathrm{D}_{2} \mathrm{O}$ (Figure $\mathrm{S} 2$ ) revealed the presence of a high number of aliphatic protons and only a few peaks in the (hetero)aromatic region corresponding to pyridone derivatives. ${ }^{37}$ Despite the broadening of the peaks, it is clear that no traces of unreacted citric acid or diethylene triamine were observed. Because of the complexity of the NMR spectrum, infrared (IR) spectroscopy and X-ray photoelectron spectrometry (XPS) were used to get additional information on the nature of the chemical bonds in the nanoparticles. As shown in Figure 1E, the IR spectrum reveals the presence of amine $\left(\delta_{\mathrm{N}-\mathrm{H}}\right)$, aliphatic $\mathrm{C}-\mathrm{C}\left(\delta_{\mathrm{C}-\mathrm{C}}\right)$, and aromatic $\mathrm{C}-\mathrm{H}\left(\delta_{\mathrm{C}-\mathrm{H}}\right)$ bonds in the low energy range $(\sigma<$ $\left.1100 \mathrm{~cm}^{-1}\right)$. The spectrum also indicates the presence of tertiary alcohol $\left(\delta_{\mathrm{O}-\mathrm{H}}\right.$ and $\left.\nu_{\mathrm{C}-\mathrm{O}}\right)$, amine $\left(\nu_{\mathrm{C}-\mathrm{N}}\right)$, and ester $\left(\nu_{\mathrm{C}-\mathrm{O}}\right)$ in the $1100-1400 \mathrm{~cm}^{-1}$ range. Secondary and tertiary amides are also present in the nanoparticles as indicated by peaks at 1560 and $1658 \mathrm{~cm}^{-1}\left(\nu_{\mathrm{C}-\mathrm{N}}\right.$ and $\nu_{\mathrm{C}=\mathrm{O}}$, respectively). Finally, the IR spectrum reveals strong intramolecular interactions through hydrogen bonding, as evidenced by the broad band in the $3000-3500 \mathrm{~cm}^{-1}$ spectral range. Stretching modes from $\mathrm{O}-\mathrm{H}$ bonds of alcohol and carboxylic groups are also observed (3086 and $3285 \mathrm{~cm}^{-1}$, respectively). The presence of numerous amines and carboxylic groups explains the very high solubility of FONPs in water $(>250 \mathrm{~g} / \mathrm{L})$.

XPS measurements (Figures $1 \mathrm{~F}$ and S3 and Table S2) corroborate the low amount of aromatic moieties within FONPs. We stress that Raman spectroscopy demonstrates that the nanoparticles do not contain graphene-like structures (Figure S4). In summary, the complementary experimental characterization techniques indicate that our FONPs are made 

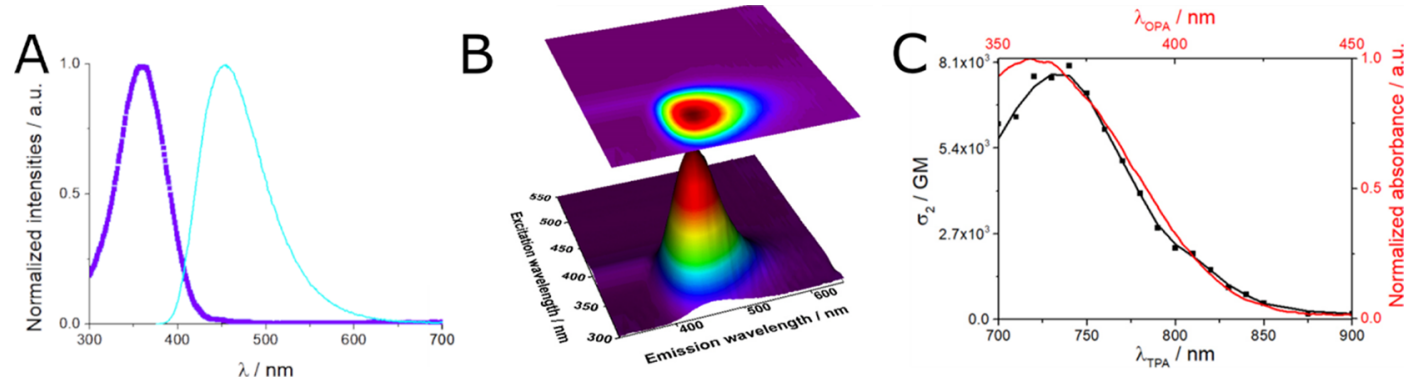

Figure 2. (A) Normalized absorption (purple) and emission (cyan) spectra of nanoparticles in water; (B) normalized three-dimensional (3D) excitation and emission spectra of nanoparticles in water; and (C) 2PA spectrum (black) compared to rescaled one-photon absorption spectrum (red) of FONPs in water.
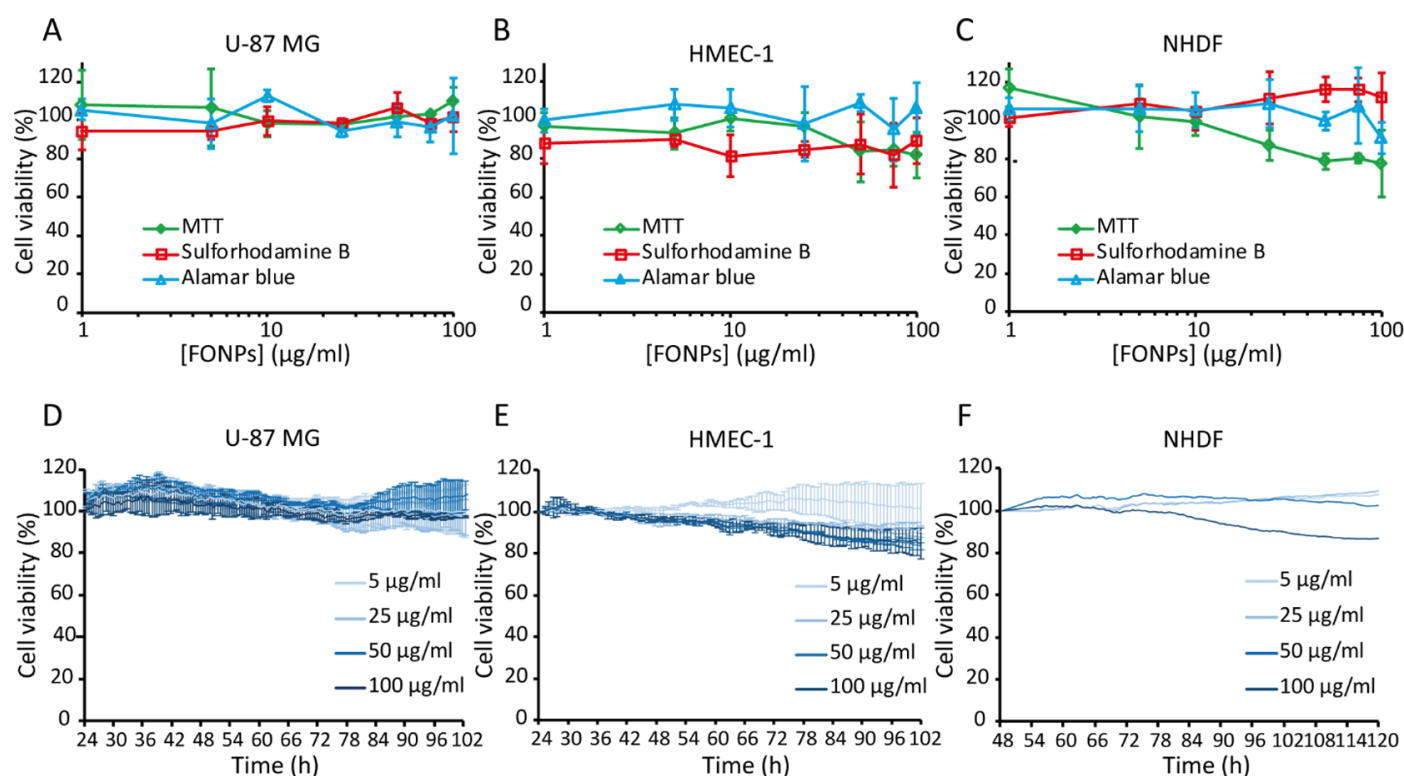

Figure 3. Colorimetric cell survival assays performed after $72 \mathrm{~h}$ of incubation of FONPs (1-100 $\mu \mathrm{g} / \mathrm{mL}$ ) with U-87 MG cells (A), HMEC-1 (B), and NHDF (C) and the real-time impedance-based survival assay performed over a period of $72 \mathrm{~h}$ after treatment with FONPs $(5-100 \mu \mathrm{g} / \mathrm{mL})$ for U-87 MG cells (D), HMEC-1 (E), and NHDF (F). MTT: 3-(4,5-dimethylthiazol-2-yl)-2,5-diphenyltetrazolium bromide.

of organic polymeric chains (made from ester and amide linkages) in which (hetero)aromatic moieties are embedded. We also stress that the size of FONPs is larger than those usually reported for the carbogenic nanoparticles (CDs) whose size is typically smaller than $10 \mathrm{~nm} .^{27}$

Thanks to the presence of the embedded heteroaromatic moieties, such as previously reported pyridone derivatives in CDs originating from the pyrolysis of citric acid and diamines, ${ }^{37}$ FONPs show an intense absorption band in the near UV region with a maximum at $360 \mathrm{~nm}$, as well as bright blue fluorescence in water when excited in the near UV region (Figure 2). The emission spectrum shows a maximum at 455 $\mathrm{nm}$ (Figure 2A). Interestingly, no dependence of the emission on the excitation wavelength was noticed (Figure 2B), contrarily to what was reported for quantum-sized fluorescent CDs. ${ }^{42}$ This behavior is typical of molecular emitting dyes. Moreover, FONPs are excellent absorbers having a high excitation coefficient $\left(\varepsilon^{\max }\right)$ value $\left(\sim 30 \times 10^{6} \mathrm{~mol}^{-1} \cdot \mathrm{cm}^{-1}\right)$ and good emitters in water (quantum yield $\Phi_{\mathrm{f}}=0.14$ ) (Table S3). As a result, FONPs show large brightness $\left(\varepsilon^{\max } \Phi_{\mathrm{f}}=4 \times 10^{6}\right.$ $\mathrm{mol}^{-1} \cdot \mathrm{cm}^{-1}$ ) in water.

Thanks to their fluorescence properties, the two-photon absorption (2PA) properties of FONPs in the near-IR region could be investigated by performing two-photon excited fluorescence (TPEF) experiments in solution. As shown in Figure 2C, FONPs show large 2PA cross section $\left(\sigma_{2}\right)$ in the $700-770 \mathrm{~nm}$ region, originating from a two-photon transition to the same excited state as the one reached by one-photon absorption in the near UV region (Figure 2C). A maximum 2PA cross section of $7700 \mathrm{GM}$ was determined at $730 \mathrm{~nm}$, leading to large two-photon brightness $\left(\sigma_{2}^{\max } \Phi_{\mathrm{f}}=1080 \mathrm{GM}\right)$. We stress that the photophysical properties of FONPs, which include a fluorescence lifetime of $1.5 \mathrm{~ns}$, are consistent with photoluminescence properties originating from isolated heteroaromatic emitters (typically 2-pyridones) embedded in the FONP matrix. In contrast, QCDs show different behavior because of the different origin of luminescence properties (i.e., extended $\pi$-electron conjugation in graphitic/graphene domains). These domains explain the larger $2 \mathrm{PA}$ values reported for QCDs (typically $40000 \mathrm{GM})^{42}$ compared to our FONPs whose 2PA properties originate from the additive contribution of a number of small dyes (typically pyridones) embedded in the FONP polymeric matrix. Yet, QCDs require surface passivation for maintaining large fluorescence quantum yields, otherwise quenching of fluorescence being observed. In contrast, FONPs combine remarkable solubility in aqueous media as well as steady fluorescence in various aqueous media (vide infra). Their easy/efficient surface functionalization (vide 


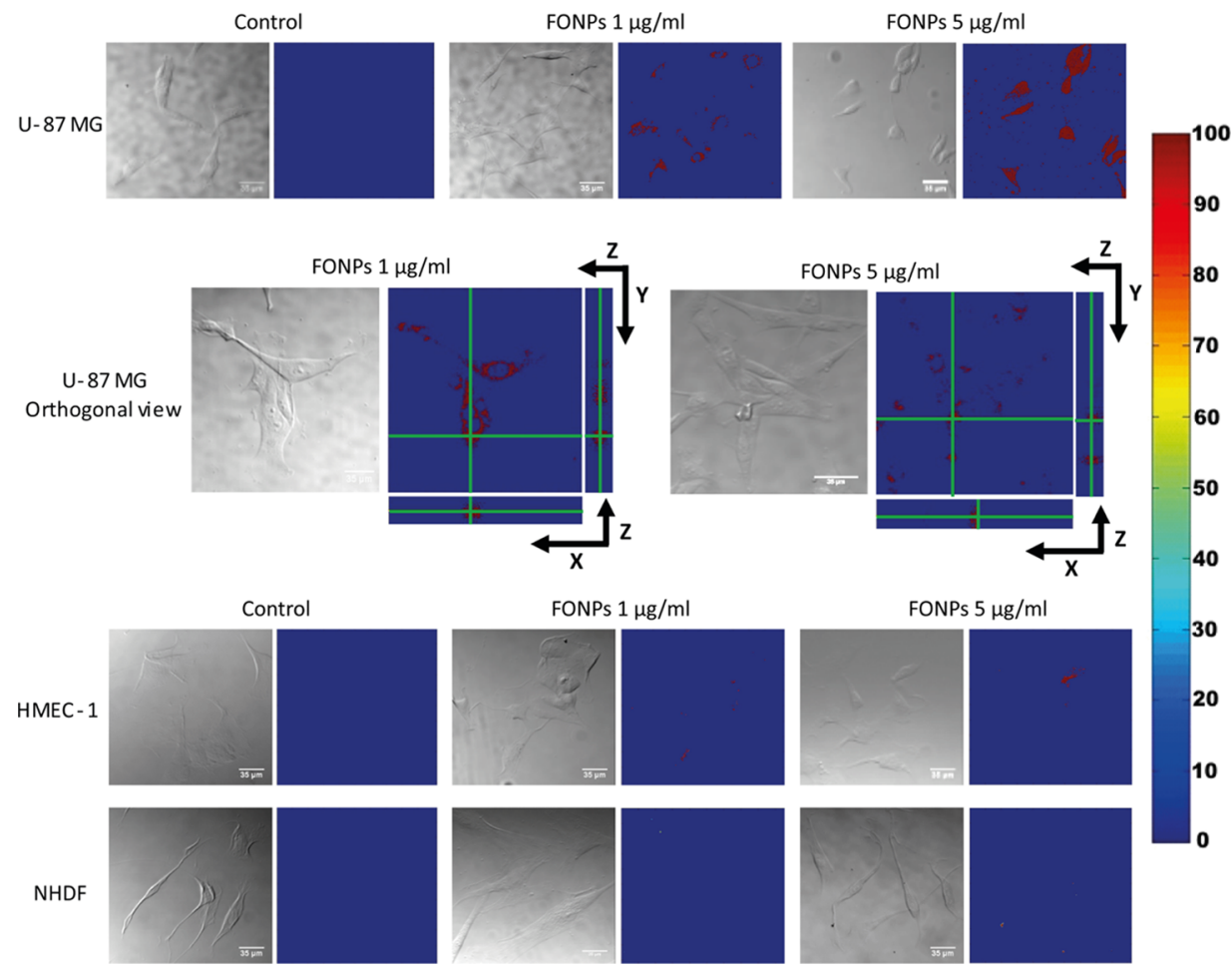

Figure 4. Two-photon fluorescence images of U-87 MG cells (upper panel) and HMEC-1 and NHDF (lower panel) after incubation for $4 \mathrm{~h}$ with FONPs $(1$ or $5 \mu \mathrm{g} / \mathrm{mL})$, upon excitation at $740 \mathrm{~nm}$ and emission detection in the $480-550 \mathrm{~nm}$ range, after autofluorescence correction. Orthogonal views showing the distribution of FONPs in the thickness of the cells are presented for U-87 MG cells (middle panel). Transmission images are provided to locate the cells. Scale bar: $35 \mu \mathrm{m}$.

infra) and large one- and two-photon brightness made them of major interest as intrinsically luminescent nanocarriers whose cellular uptake can be tracked by in vitro fluorescence imaging.

Safety and Uptake of FONPs in Human Cell Lines. Before assessing the safety and cell uptake of our FONPs, we studied the evolution of their fluorescence properties under varying conditions of $\mathrm{pH}$, medium, temperature, and concentration to check that FONPs retain fluorescence in different biological conditions. The nanoparticles dispersed in water $(25 \mu \mathrm{g} / \mathrm{mL})$, at room temperature, show steady fluorescence in the 4-11 pH range, while only a slight decrease (less than $10 \%$ ) in the fluorescence emission was observed at highly acidic $\mathrm{pH}(\mathrm{pH}=2-3$, Figure S5A(i)). This can be related to the change of protonation state of the $\mathrm{CO}_{2} \mathrm{H}$ surface. When dispersed in complete cell culture medium [i.e., Dulbecco's modified Eagle's medium (DMEM) without phenol red, with $10 \%$ fetal bovine serum (FBS)] at $37{ }^{\circ} \mathrm{C}$, to mimic physiological conditions, FONPs $(25 \mu \mathrm{g} / \mathrm{mL})$ did not show changes in fluorescence emission for $72 \mathrm{~h}$ (Figure $\mathrm{S} 5 \mathrm{~B}(\mathrm{ii})$ ). The fluorescence emission of FONPs was also found to remain unaffected at a higher concentration $(100 \mu \mathrm{g} / \mathrm{mL})$ in various media at 37 and $4{ }^{\circ} \mathrm{C}$ for $72 \mathrm{~h}$ (Figure S6).

The FONP safety was then investigated in three human cell lines. One cancerous cell line (U-87 MG human glioblastoma cell line) and two noncancerous cell lines [human microvascular endothelial cells (HMEC-1) and normal human dermal fibroblasts (NHDF)] were used to compare and evaluate the potential of FONPs as drug delivery vehicles for glioblastoma treatment. Three colorimetric cell survival assays based on the metabolic activity of mitochondria or the protein biomass were used for this purpose. A label-free, impedancebased real-time assay was also used, which reflects variation of impedance as a function of cell adhesion to the surface. All these methods allow the determination of the number of living cells. Cell viability was measured after incubation of cells with FONPs at concentrations ranging from 1 to $100 \mu \mathrm{g} / \mathrm{mL}$ for 72 h. U-87 MG cells showed no reduction in cell viability up to the concentration of $100 \mu \mathrm{g} / \mathrm{mL}$ (Figure 3A) regardless of the test used. Inhibition of HMEC-1 cell and NHDF cell survival of less than $20 \%$ was observed whatever the employed colorimetric test (Figure 3B,C). Real-time continuous monitoring of impedance for $72 \mathrm{~h}$ confirmed these results (Figure $3 \mathrm{D}-\mathrm{F}$ ), suggesting a good safety profile of FONPs in the human cell lines.

FONPs hence show excellent biocompatibility and do not require surface passivation in contrast with common $\mathrm{CDs} .{ }^{43}$ The existing literature on the cytotoxicity of CDs demonstrates differential effects or lack of toxicity depending on various factors such as the nature and synthesis process, type of cells, duration of treatment, and range of concentrations and often solely relies on a single colorimetric assay. ${ }^{44-46} \mathrm{~A}$ few studies demonstrated the safety of CDs in both cancerous and noncancerous cell lines, but the concentration of CDs which was used for imaging was higher than the concentration range in which the cytotoxicity assays were performed. ${ }^{4-49}$ Here, we demonstrated the safety of our FONPs using multiple assays (colorimetric and noncolorimetric) to eliminate potential over estimation or underestimation of cell survival because of the interference of nanoparticles with test reagents. ${ }^{50}$ Along with their safety, it was necessary to ensure that FONPs are internalized in glioblastoma cells for future applications in therapy. Internalization of FONPs was studied at varying concentrations in U-87 MG, HMEC-1, and NHDF cell lines using two-photon fluorescence imaging (excitation at $740 \mathrm{~nm}$ 
and emission detection from 480 to $550 \mathrm{~nm}$ ). Because of the autofluorescence of control cells (not treated with nanoparticles) at these excitation and emission wavelengths, the cells treated with nanoparticles were corrected for autofluorescence using control cell images obtained under the same conditions. Transmission images were also obtained along with the fluorescence images to locate the cells. At $4 \mathrm{~h}$ of incubation with FONPs, there was a qualitatively high uptake at 1 and 5 $\mu \mathrm{g} / \mathrm{mL}$ concentrations in U-87 MG cells (Figure 4, upper panel) with negligible uptake in HMEC-1 and NHDF cell lines (Figure 4, lower panel). Images obtained at the FONP concentration of $25 \mu \mathrm{g} / \mathrm{mL}$ for U-87 MG cells, HMEC-1, and NHDF are shown in Figure S7, and a slight increase in uptake was observed in HMEC-1 cells at this concentration but was not uniform in all cells. The localization of nanoparticles in U87 MG cells was also demonstrated by obtaining $Z$ stack images along the thickness of the cell (Figure 4). The $X Y$ fluorescence images with corresponding $X Z$ and $Y Z$ orthogonal views show uniform distribution of fluorescence along the $Z$. An additional human glioblastoma cell line (U-251 MG) also showed considerable uptake of nanoparticles compared to HMEC-1 and NHDF cell lines at $4 \mathrm{~h}$ incubation (Figure S8).

The two-photon imaging of carbon nanodots has not been commonly used for in vitro internalization studies ${ }^{46,51,52}$ but mostly for Förster resonance energy transfer -based imaging and photodynamic therapy, ${ }^{53}$ for tracking drug delivery, ${ }^{54}$ or for in vivo imaging. ${ }^{46}$ The existing studies on in vitro internalization of fluorescent CDs using two-photon microscopy predominantly use one cell type, and there is also lack of information on autofluorescence background in control cells not treated with CDs. Herein, we have demonstrated the variation in the internalization of our FONPs with respect to concentration across four different cell lines (two cancerous and two noncancerous), with preferential uptake in glioblastoma cells. This major finding is of importance with respect to chemotherapy issues. This remarkable preferential internalization could be related to differences in the cell membrane structure and function depending on the cell type. For example, $\alpha \mathrm{V} \beta \mathrm{III}$ integrin and SPARC or gp60 are overexpressed in glioblastoma cells and have been mentioned to be responsible for preferential uptake of nanoparticles in U-87 MG or C6 glioma cells. ${ }^{49,55}$

To decipher the mechanism of cell uptake, U-87 MG cells were incubated with FONPs at $4{ }^{\circ} \mathrm{C}$. Negligible internalization was observed at reduced temperature, which suggests an energy-dependent uptake (Figure S9). The U-87 MG cells were also treated with clathrin inhibitor (chlorpromazine), caveolin inhibitor (genistein), and lipid raft inhibitor (methyl beta cyclodextrin). It was observed that blocking clathrin did not have a pronounced effect on the uptake of nanoparticles, while blocking caveolin or lipid rafts reduced the uptake drastically when compared to control cells (Figure S9). These observations suggest that the uptake mechanism is predominantly mediated by caveolin-based and lipid raft-based endocytosis. It has been previously demonstrated that the protein corona influenced gold nanoparticle uptake: indeed, gold nanoparticles of $20 \mathrm{~nm}$ were predominantly internalized by a caveolin route, while a clathrin-mediated pathway was promoted by the presence of protein corona for larger $(50 \mathrm{~nm})$ gold nanoparticles in murine macrophage and human liver cancer cells. ${ }^{56}$ Hence, we infer that the protein corona that would form when FONPs are diluted in complete cell culture medium, in combination with their size, promote preferential internalization by glioblastoma cells, predominantly through caveolin-based and lipid-raft-based uptake. Understanding the mechanism of these soft hydrophilic organic nanoparticles' uptake is significant to design better drug vehicles for glioblastoma therapy. To the best of our knowledge, this is the first time that this is described for such nanoparticles in glioblastoma cells. The safety and internalization of our FONPs have been demonstrated on different human cell lines, making them suitable candidates for use as drug delivery systems. We thus took advantage of the high solubility of FONPs in water and the presence of amines on their surface to synthesize water-soluble nanoparticles linked to PTX (FONPs-PTX).

Synthesis of FONPs-PTX. As the nanoparticles possess chemically accessible amine and carboxylic acid groups, our strategy was to use a spacer between the FONPs and PTX; the spacer must be (i) long enough to favor the bioavailability of the drug and (ii) short enough to protect the drug from degradation until the nanoparticles reached the cancer cells. Keeping this in mind, we chose the succinic acid as a linker. This linker can be easily covalently bonded to the nanoparticles by a ring-opening reaction of the amines of the FONPs onto the succinic anhydride molecule, leading to the formation of a stable amide bond (Scheme 1, step 2). Once the nanoparticles were functionalized with succinic acid, PTX was bonded to the terminal $\mathrm{CO}_{2} \mathrm{H}$ groups via an ester bond on the position $\mathrm{C}^{\prime}$ of the side chain of PTX (Scheme 1 step 3), where the most reactive alcohol function is located. This free alcohol is mandatory to the bioactivity of PTX and can be esterified. ${ }^{57}$ It is thus a suitable functional group for attaching PTX to nanoparticles while masking its toxicity. The resulting prodrug is expected to be nontoxic until intracellular lysis of the ester linkage, diminishing systemic toxicity. Furthermore, the drug release will occur faster than the hydrolysis of acetate or the side-chain cleavage, which would destroy the anticancer activity.

Characterization of FONPs-PTX. The amount of PTX grafted on the nanoparticles was determined by NMR dosing. The final amount of PTX is about $4.5 \%$ of the total weight of the nanoparticles. Despite the significant amount of PTX per nanoparticle, the dry size of FONPs-PTX remains close to 20 $\mathrm{nm}$ (Figure 1B), which suggests that PTX is mainly located inside the nanoparticles, which provides a better environment compared to the charged surface. The presence of the hydrophobic drug within the nanoparticle is in good agreement with the excellent water solubility of FONPs-PTX which is higher than $9 \mathrm{mg} / \mathrm{mL}$ (higher concentrations could not be tested because of the available amount of FONPs-PTX), therefore its solubility is much higher than the solubility of free PTX in water (less than $0.01 \mathrm{mg} / \mathrm{mL}$ ). Such confinement of the cytotoxic drug within FONPs is a further asset with regard to reduced systemic toxicity. The stability of the bond between PTX and FONPs has been verified in storage conditions (FONPs-PTX dispersed in ultrapure water at $10 \mathrm{mg} / \mathrm{mL}$ and stored at $4{ }^{\circ} \mathrm{C}$ ) up to 8 weeks.

In Vitro Antitumor Activity of FONPs-PTX. Before assessing the antitumor activity of FONPs-PTX against glioblastoma cells, we first studied the stability of the bond between FONPs and PTX in biological conditions (complete cell culture medium, $37{ }^{\circ} \mathrm{C}$, final PTX-equivalent concentration $10 \mu \mathrm{M})$ over 2 weeks. High-performance liquid chromatography (HPLC) was used to quantitatively determine the presence of free PTX that could be released from FONPs- 
PTX (Figure S10). ${ }^{58}$ No specific peak of PTX was detected above the limit of quantification $(10 \mathrm{nM})$ up to 2 weeks, revealing the absence of burst release and the stability of the covalent bond between PTX and nanoparticles. These results suggest that a premature drug release in blood by the action of hydrolytic enzymes could be avoided with our system, which would lead to lower systemic toxicity than that of free PTX in vivo.

As FONPs-PTX proved to be stable and bare nanoparticles proved to be safe, we then investigated whether the binding of PTX to nanoparticles would alter the drug properties and whether PTX could be released intracellularly. In twodimensional (2D) cell culture, a classical MTT assay was performed on U-87 MG (glioblastoma cell line) for $72 \mathrm{~h}$, demonstrating a dose-dependent anticancer activity of FONPs-PTX, which reached a maximal effect at $80 \%$ of cell survival inhibition at the highest doses (Figure 5A). In U-87
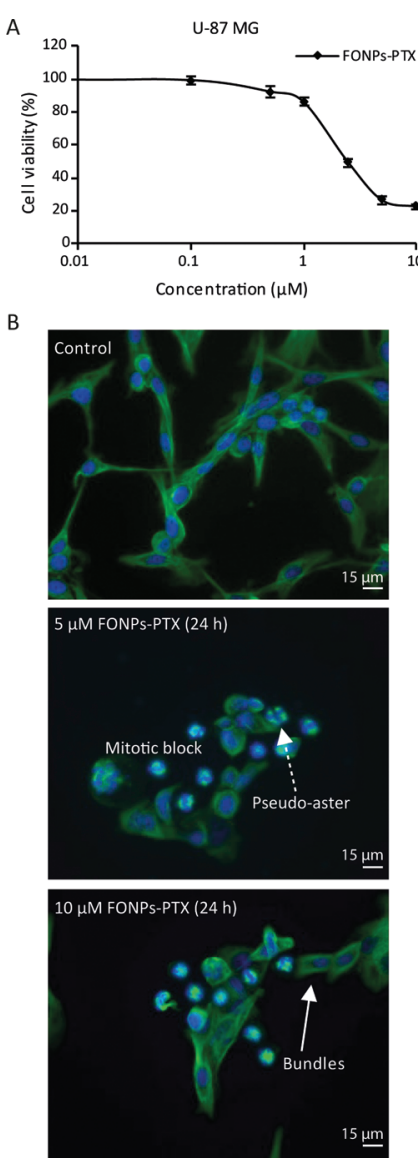

Figure 5. Inhibition of cell viability by FONPs-PTX in $2 \mathrm{D}$ glioblastoma cell culture. (A) MTT assay on U-87 MG cells treated with FONPs-PTX for $72 \mathrm{~h}$. (B) Immunofluorescence imaging of the microtubular network and nuclei $(40 \times)$ in U-87 MG cells untreated (control) or incubated with FONPs-PTX (5 or $10 \mu \mathrm{M})$ for $24 \mathrm{~h}$. Bundles (full arrow), pseudo-asters (dotted arrow), and mitotic block are typical of the PTX pharmacological effect.

MG cells, FONPs-PTX showed a lower inhibition of cell survival (concentration that inhibits $50 \%$ of cell survival $\mathrm{IC}_{50}=$ $2.5 \pm 0.1 \mu \mathrm{M})$ than PTX alone $\left(\mathrm{IC}_{50}=10.8 \pm 1.6 \mathrm{nM}\right)$, suggesting a delayed effect of the conjugate because of the time needed for intracellular enzymes to cleave PTX from nanoparticles, as previously observed. ${ }^{7-9}$ Gomez et al. have recently shown that PTX-coupled nitrogen-doped carbon nanodots by an ester bond exhibit a better anticancer activity compared to free PTX in several cell lines. ${ }^{59}$ In our work, we demonstrated that PTX is not released from the prodrug in biological medium at $37{ }^{\circ} \mathrm{C}$. We thus expected that the observed cytotoxicity might be the result of a cleavage of the bond between PTX and the FONPs after cell uptake. Importantly, the binding of PTX to nanoparticles and its further release did not alter the drug properties, as the PTXspecific pharmacological effects on the microtubular network were visualized after U-87 MG cell treatment for $24 \mathrm{~h}^{60}$ Indeed, the control cells displayed a fine network of microtubules irradiating from the centrosomes, whereas bundles of microtubules, pseudo-asters, and mitotic block were observed in FONPs-PTX-treated cells (Figure 5B). These data indicate that FONPs-PTX can be considered as a prodrug of PTX.

Finally, we investigated the anticancer activity of the prodrug FONPs-PTX in 3D culture systems which have more realistic morphology, phenotype, and cellular heterogeneity of cancer cells than in $2 \mathrm{D}$ culture. ${ }^{61}$ The independence from culture plastic substrates in $3 \mathrm{D}$ culture facilitates a cellular architecture more similar to cell organization in vivo than in $2 \mathrm{D}$ culture. In addition, spheroids have limited transport capacity for drugs, nutrients, and other factors comparable to in vivo tissues. It is now admitted that spheroids allow a better in vitro anticancer evaluation of a prodrug before a full development program of the efficacy and safety evaluation required for new chemical entities. ${ }^{62}$ We first confirmed the safety of FONPs (181 or 362 $\mu \mathrm{g} / \mathrm{mL}$ ) in $3 \mathrm{D}$ culture for 13 days. Spheroids treated with FONPs did not present evident morphological alterations (Figure 6A), nor was there a statistically significant difference with untreated control spheroids in spheroid cross-sectional area (Figure 6B) or cell viability (Figure 6C). We then studied the anticancer activity of FONPs-PTX at the same concentrations as bare nanoparticles, corresponding to 5 or $10 \mu \mathrm{M}$ PTX-equivalent concentration. Spheroids treated with FONPs-PTX from $5 \mu \mathrm{M}$ exhibited irregular shapes as compared to untreated control spheroids or spheroids treated with bare nanoparticles (Figure 6A). We observed a statistically significant smaller cross-sectional area of spheroids treated for 13 days with FONPs-PTX as compared to controls by $37 \pm 9 \%(p<0.01)$ and $80 \pm 6 \%(p<0.001)$ for 5 and $10 \mu \mathrm{M}$, respectively (Figure $6 \mathrm{~B}$ ), showing that the FONP-PTX anticancer activity was dose-dependent. Furthermore, the dose-dependent effect increases with time because the difference in cross-sectional area between spheroids treated with 5 and $10 \mu \mathrm{M}$ was $29 \pm 12 \%(p<$ $0.05)$ at day 3 and $68 \pm 10 \%(p<0.01)$ at day 13 . The viability assay performed on spheroids after 13 days' exposure to $10 \mu \mathrm{M}$ confirms the anticancer activity of FONPs-PTX (Figure 6C), as it results in a decrease in cell survival of $69 \pm 11 \%(p<$ $0.001)$. Therefore, the decrease in area of the treated spheroids can be related to an inhibition of cell viability. Importantly, because the PTX bond to nanoparticles is stable in complete cell culture medium at $37{ }^{\circ} \mathrm{C}$ for 2 weeks, the observed anticancer effect is likely due to the intracellular release of PTX from FONPs-PTX. Finally, our study confirms the interest of a formulation consisting of a covalent binding of PTX to our soft hydrophilic organic nanoparticles. This covalent bond ensures satisfactory biological stability and a cytotoxic effect against glioblastoma cells, thus opening the way to in vivo studies of efficacy and safety of FONPs-PTX. 


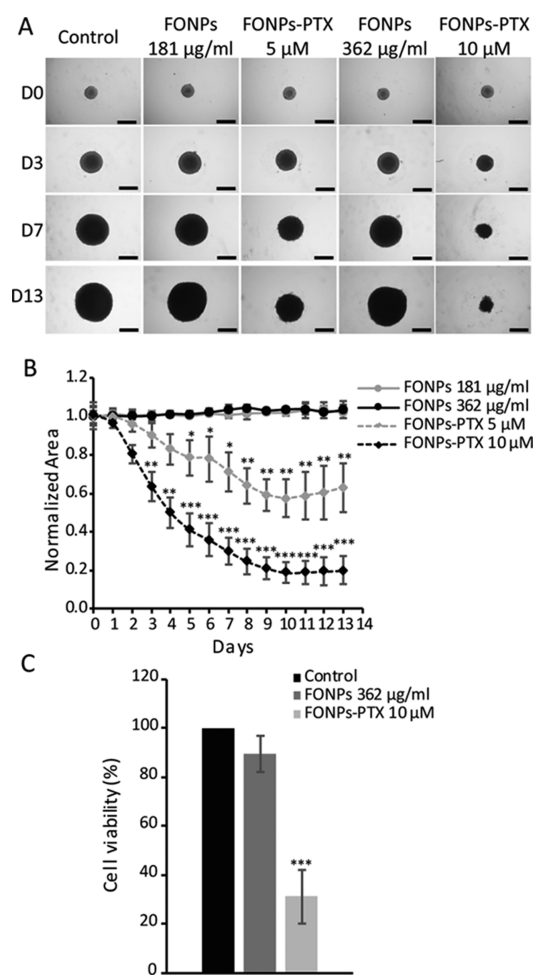

Figure 6. Safety of FONPs and anticancer activity of FONPs-PTX in 3D cell culture. (A) Phase-contrast microscopy (4X) of U-87 MG spheroid control and treated with FONPs or FONPs-PTX for 13 days (scale bar $=500 \mu \mathrm{m}, \mathrm{D}=$ day). (B) Time- and dose-dependent effect of FONPs-PTX and absence of activity of FONPs on the area of spheroids (normalized area to untreated control spheroids) until 13 days. (C) Alamar blue assay on spheroids after 13 days of treatment with FONPs $(362 \mu \mathrm{g} / \mathrm{mL})$ or FONPs-PTX $(10 \mu \mathrm{M})$ compared to untreated control spheroids.

\section{CONCLUSIONS}

Thanks to their unique combination of high solubility in water, innocuousness, large one- and two-photon brightness, and high covalent loading ability, FONPs obtained from citric acid and DETA appear as highly promising nanocarriers for hydrophobic drugs. In addition, two-photon fluorescence imaging experiments revealed that these nanoparticles show preferential internalization in glioblastoma cancer cells, making them a suitable candidate for use as drug delivery systems. Considering these advantages, PTX was covalently linked to the nanoparticles, leading to FONPs-PTX with excellent solubility and reasonable stability in water. The antitumor activity of FONPs-PTX was demonstrated in vitro on both $2 \mathrm{D}$ and $3 \mathrm{D}$ culture. PTX is released from the nanoparticles in its active form only after cell internalization, thanks to the nature of covalent bond (ester linkage). These results demonstrate that FONPs are promising nanotools for formulating PTX as a prodrug to improve its benefit/risk ratio, in particular in glioblastoma treatment. Thanks to their versatile surface functionalization, additional grafting of targeting units and clinically approved fluorescent tags would be of major interest to extend their use in image-guided surgery and adjuvant therapy of glioblastoma. We are currently exploring this route.

\section{EXPERIMENTAL SECTION}

Synthesis. Synthesis of the FONP Platform. In a $25 \mathrm{~mL}$ round flask, monohydrate citric acid $(1.05 \mathrm{~g}, 5.0 \mathrm{mmol})$ was dissolved in water $(1 \mathrm{~mL})$, and then diethylene triamine (1.0 $\mathrm{mL}, 9.2 \mathrm{mmol}$ ) was added. The resulting solution was heated using a standard microwave oven for $2 \mathrm{~min}$ at $600 \mathrm{~W}$. As the residue cooled down, $95 \%$ ethanol $(5 \mathrm{~mL})$ was added, and the suspension was scratched with a spatula until the formation of a thin slightly brown powder. After sonication for $2 \mathrm{~min}$, the homogeneous suspension was centrifuged at $10800 \mathrm{rpm}$ for 10 min. The brownish powder at the bottom of the centrifuge cylinder was collected and washed with isopropanol and then with diethyl ether to yield $1.2 \mathrm{~g}$ of FONPs after complete drying (under vacuum). The amount of chemically accessible amine per milligram of FONPs was $0.7 \mu \mathrm{mol}$ (Kaiser test, see below).

Synthesis of the Activated FONPs. In a $10 \mathrm{~mL}$ cylindrical flask, the FONP platform ( $200 \mathrm{mg}, 0.14 \mathrm{mmol}$ of amine) was dissolved in dimethyl sulfoxide (DMSO) $(2 \mathrm{~mL})$, and then $\mathrm{Na}_{2} \mathrm{CO}_{3}(850 \mathrm{mg}, 8.0 \mathrm{mmol})$ was added, followed by succinic anhydride ( $400 \mathrm{mg}, 4 \mathrm{mmol}$ ). The reaction mixture was stirred at room temperature overnight. Following neutralization of the excess of $\mathrm{Na}_{2} \mathrm{CO}_{3}$ by $\mathrm{HCl}(1 \mathrm{~N})$, the $\mathrm{pH}$ was adjusted at 4 . The resulting solution was frozen and lyophilized. The residue was dissolved in ethanol and then centrifuged to remove insoluble inorganic salts. The supernatant was collected, and the solvent was evaporated under reduced pressure to yield $125 \mathrm{mg}$ of activated FONPs as a brownish powder.

Synthesis of FONPs-PTX. In a $25 \mathrm{~mL}$ round flask, activated FONPs $(90.0 \mathrm{mg})$ were dissolved in dry dimethylformamide (DMF) $(5.0 \mathrm{~mL})$, followed by the addition of a crystal of dimethylaminopyridine and PTX $(13.5 \mathrm{mg}, 15.8 \mu \mathrm{mol})$. Then, $\mathrm{N}$-(3-dimethylaminopropyl)- $\mathrm{N}^{\prime}$-ethylcarbodiimide hydrochloride $(13.9 \mathrm{mg}, 72.6 \mu \mathrm{mol})$ was added, and the solution was stirred at room temperature for $60 \mathrm{~h}$. At the end of the reaction, water was added to the solution, and the solvent was evaporated under reduced pressure. The residue was suspended in acetone, the suspension was centrifuged, and then the powder was collected. The washing step with acetone was repeated four times, and the resulting powder was dissolved in water and purified on Sephadex LH20 eluting with water. The fractions containing the good product were collected, and then the resulting solution was frozen and lyophilized to yield $78.7 \mathrm{mg}$ of FONPs-PTX as a brownish powder.

Characterization of FONPs and FONPs-PTX. Elemental Analysis. The elemental concentrations of the FONPs were determined on a $\mathrm{CNH}$ analyzer at ICSN-CNRS at Gif-surYvette (France).

Transmission Electron Microscopy. The size of the FONPs was determined by TEM imaging which was carried out on a HITACHI H7650 at $80 \mathrm{kV}$. Copper grids coated with a carbon membrane were pretreated using the glow discharge technique to get positively charged surface, thus helping the interaction between the FONPs and the grid. One droplet of the aqueous FONP solution was deposited on the grid; the excess of liquid was gently drawn off with paper, and the sample was further stained with uranyl acetate. The FONPs were randomly and manually counted using ImageJ program (using a circle selection); the diameter of each FONP was measured, and the results were given as a medium size (diameter) of the 
overall counted FONPs. For the statistics, 415 FONPs were counted.

Atomic Force Microscopy. The morphology of the FONPs was analyzed by AFM using the following procedure. A volume of $5 \mu \mathrm{L}$ of the solution in water was deposited onto freshly cleaved mica disks and left at room temperature until dryness. AFM was carried out with a Dimension Icon, operated in peak force mode. The probes used were ScanAsyst-Air (Bruker). The set point in peak force mode was $500 \mathrm{pN}$, and the scan rate was $0.250 \mathrm{~Hz}$. The images were processed with NanoScope Analysis 1.5 program.

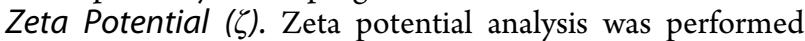
with a SZ-100Z HORIBA instrument. Ten measurements were realized for each sample according to a predefined operating procedure, and the final values were calculated as an average of the overall measurements.

IR and Raman Spectroscopies. Fourier transform IR spectra of FONPs were recorded from the $\mathrm{KBr}$ pellet on a PerkinElmer Spectrum 100 Optica spectrometer. Raman spectra were recorded on powders of the FONPs using an Explora Raman microscope (HORIBA) working at $785 \mathrm{~nm}$ with an air objective $\times 50$.

$X$-ray Photoelectron Spectrometry. XPS measurements were performed at PLACAMAT in Bordeaux (France) using a K-Alpha spectrometer (ThermoFisher).

UV-Visible Absorption and Fluorescence Spectroscopies. All photophysical properties were analyzed with freshly prepared air-equilibrated solutions at room temperature (293 $\mathrm{K})$. UV/vis absorption spectra were recorded using a Jasco V570 spectrophotometer. Steady-state fluorescence measurements were performed on diluted solutions (optical density < 0.1 ) contained in standard $1 \mathrm{~cm}$ quartz cuvettes using a HORIBA FluoroMax spectrometer in photon-counting mode. Fully corrected emission spectra were obtained for each compound at $\lambda_{\mathrm{ex}}=\lambda_{\mathrm{abs}}^{\max }$ with an optical density at $\lambda_{\mathrm{ex}} \leq 0.1$ to minimize internal absorption. Fluorescence quantum yields were measured according to literature procedures using fluorescein in $0.1 \mathrm{M} \mathrm{NaOH}\left(\Phi_{\mathrm{f}}=0.9\right)$ or quinine bisulfate in $1 \mathrm{~N} \mathrm{H}_{2} \mathrm{SO}_{4}\left(\Phi_{\mathrm{f}}=0.546\right)$.

Two-Photon Absorption. 2PA cross sections $\left(\sigma_{2}\right)$ were determined from the TPEF cross sections $\left(\sigma_{2} \Phi_{\mathrm{f}}\right)$ and the fluorescence emission quantum yield $\left(\Phi_{\mathrm{f}}\right)$. TPEF cross sections were measured relative to fluorescein in $0.01 \mathrm{M}$ aqueous $\mathrm{NaOH}$ at $680-900 \mathrm{~nm}^{63}$ for FONPs using the wellestablished method described by $\mathrm{Xu}$ and $\mathrm{Webb}^{64}$ and the appropriate solvent-related refractive index corrections. ${ }^{65}$ The quadratic dependence of the fluorescence intensity on the excitation power was checked for each sample and all wavelengths. Measurements were conducted using an excitation source delivering femtosecond pulses, thus avoiding excited-state absorption during the pulse duration, a phenomenon which has been shown to overestimate TPA cross-sectional values. The laser beam was focused into the cuvette through a microscope objective (10×, NA 0.25). The fluorescence emission was detected in epifluorescence mode via a dichroic mirror (Chroma 675dcxru) and a barrier filter (Chroma e650sp-2p) by using a compact CCD spectrometer module BWTek BTC112E. Total fluorescence intensities were obtained by integrating the corrected emission. The experimental uncertainty of the action cross-sectional values determined by this method has been estimated to be $\pm 10 \%$.

Dosing of the Chemically Surface Reactive Amine Groups. The amount of chemically available amines per weight of FONPs was determined using the Kaiser test. In a test tube, $20 \mu \mathrm{L}$ of a solution of the FONPs in water (typical concentration $20 \mathrm{mg} / \mathrm{mL}$ ) were mixed with $100 \mu \mathrm{L}$ of a solution of ninhydrin in ethanol (6\%, Kaiser test SigmaAldrich), $100 \mu \mathrm{L}$ of a solution of phenol in ethanol (80\%, Kaiser test Sigma-Aldrich), and $100 \mu \mathrm{L}$ of a solution of potassium cyanide in pyridine (Kaiser test Sigma-Aldrich). The solution was heated at $120{ }^{\circ} \mathrm{C}$ for $5 \mathrm{~min}$ in a sand bath previously warmed. The resulting solution was left for cooling $1 \mathrm{~min}$, and $20 \mu \mathrm{L}$ of the cooled solution were dissolved in 2.0 $\mathrm{mL}$ of ethanol. The absorption spectrum of the diluted solution was recorded, and the value of the absorbance of the solution at $590 \mathrm{~nm}$ was compared to a calibrated value to determine the concentration of amine in the sample. The calibrated value was obtained by the same procedure (Kaiser test) except that the known concentration of $\beta$-alanine was used instead of the FONPs.

Dosing of PTX. In an NMR tube, FONPs-PTX $(14.5 \mathrm{mg})$ were dissolved in a solution of vanillin in DMSO- $d_{6}(600 \mu \mathrm{L}, 5$ $\mathrm{mmol} / \mathrm{L})$. The NMR spectrum was recorded, and the proton of the aldehyde of the vanillin $(\delta=9.8 \mathrm{ppm}, \mathrm{s}, 1 \mathrm{H})$ was used as an internal reference. The integral of this proton was then compared to the integral of the proton of the secondary amine of the PTX $(\delta=8.8 \mathrm{ppm}, \mathrm{d}, 1 \mathrm{H})$. A concentration of PTX of $4.5 \%$ in weight was found for FONPs-PTX.

Influence of External Parameters on FONP Fluorescence. Fluorescence evolution studies were conducted using a PerkinElmer lambda800 spectrophotometer and a HORIBA Jobin Yvon FluoroMax 3 fluorimeter.

Fluorescence Variation as a Function of $\mathrm{pH}$. FONPs were dispersed in deionized water at a concentration of $25 \mu \mathrm{g} / \mathrm{mL}$, and solutions of specific $\mathrm{pH}$ were obtained using a capillary $\mathrm{pH}$ meter by the addition of concentrated $\mathrm{NaOH}$ or $\mathrm{HCl}$ solutions without notable change in the volume of FONP solution. Blank samples of deionized water without FONPs with adjusted $\mathrm{pH}$ were also prepared. The fluorescence emission of the $\mathrm{pH}$-adjusted samples was measured on the fluorimeter with excitation at $360 \mathrm{~nm}$ and emission from 380 to $600 \mathrm{~nm}$ and corrected for the blank emission. The experiment was repeated twice, and the average spectra were plotted with wavelength. The maximum fluorescence intensity normalized with respect to the maximum fluorescence intensity at $\mathrm{pH}=6$ was plotted against $\mathrm{pH}$, and the standard deviation was calculated for the maximum fluorescence intensity at each $\mathrm{pH}$ across the two experiments.

Fluorescence Variation in Different Dispersion Media and with Varying Temperature. FONPs were dispersed in complete cell culture medium (DMEM without phenol red + $10 \%$ FBS) at concentrations of 25 and $100 \mu \mathrm{g} / \mathrm{mL}$ or in phosphate-buffered saline (PBS) at $\mathrm{pH} 7.4$ or MilliQ water at a concentration of $100 \mu \mathrm{g} / \mathrm{mL}$. The fluorescence of the FONPs dispersed in complete cell culture medium and PBS was measured immediately after dispersion and over time by maintaining the sample at 37 or $4{ }^{\circ} \mathrm{C}$. The variation of fluorescence over time was also tested under storage conditions (dispersed in water, $4{ }^{\circ} \mathrm{C}$ ). To correct for systemic variability at different time points, a standard solution of quinine sulfate was measured at each measurement. Experiments at $37{ }^{\circ} \mathrm{C}$ were repeated twice, and mean/standard deviations were calculated across these experiments. Experiments were confirmed at $4{ }^{\circ} \mathrm{C}$. FONPs dispersed in water were stored at $4{ }^{\circ} \mathrm{C}$ at a $20 \mathrm{mg} / \mathrm{mL}$ stock concentration. No aggregation or decrease of fluorescence was observed at time 
point 0 when independent samples were prepared for experiments at $37^{\circ} \mathrm{C}$.

Stability of the Bond between PTX and FONPs. Standard Solutions and Validation of the Method of Free PTX Quantification. PTX was obtained from Chemieliva and quantified by HPLC. ${ }^{58}$ Docetaxel (DTX) was obtained from Sigma-Aldrich. Stock solution of PTX was prepared in DMSO and stored at $-20{ }^{\circ} \mathrm{C}$. Chromatographic separation was performed on a Phenomenex Kinetex XD-C18 column $(2.1 \times$ $100 \mathrm{~mm}, 2.6 \mu \mathrm{m}$ ) with an Agilent 1100 Series HPLC system. Isocratic elution was performed with mobile phase composed of LC-MS grade acetonitrile $50 \%, 1 \mathrm{mM}$ ammonium acetate, and $0.05 \%$ formic acid at a flow rate of $0.3 \mathrm{~mL} / \mathrm{min}$. Column effluent was detected at $229 \mathrm{~nm}$ with a diode array detector. The acquisition data were processed with OpenLab CDS ChemStation Edition. A wash vial containing initial mobile phase was injected between samples to avoid sample carryover. Calibration standards of PTX (retention time $=3.3 \pm 0.2 \mathrm{~min}$ ) were prepared in the mobile phase to final concentrations of $10,20,40,50,75,100,250,500$, and $1000 \mathrm{nM}$ (Figure S10). The limit of quantification was determined at $10 \mathrm{nM}$. To validate the method, quality control (QC) samples were prepared in the mobile phase to final concentrations of 20, 130, and $900 \mathrm{nM}$. Weighted least squares linear regression analysis was used for the construction of calibration curves from the peak area.

Stability of the Bond between PTX and FONPs in Stock Solution. The FONPs-PTX powder was dispersed in ultrapure water (concentration of FONPs-PTX $=10 \mathrm{mg}$ / $\mathrm{mL}$ ). To remove free residual PTX, the aqueous phase was washed three times with dichloromethane until the absence of free PTX in the organic phase was confirmed by HPLC. The amount of bound PTX was determined at $27.6 \mathrm{nmol}$ per milligram of FONPs. HPLC for the quantification of free PTX was then repeated at different times from $5 \mathrm{~min}$ to 8 weeks after dispersion to assess the absence of PTX release from FONPs-PTX in storage conditions $\left(4^{\circ} \mathrm{C}\right)$. No peak specific to PTX was found, evidencing the chemical stability of ester bond between PTX and nanoparticles in stock solution for long time.

Stability of the Bond between PTX and FONPs in Cell Culture Medium. FONPs-PTX were diluted in complete cell culture medium (Eagle's minimum essential medium (EMEM) $+10 \%$ FBS) to a final concentration of $10 \mu \mathrm{M}$ equivalent-PTX and stored at $37{ }^{\circ} \mathrm{C}$. At different times $(15 \mathrm{~min}, 4 \mathrm{~h}, 24 \mathrm{~h}, 48 \mathrm{~h}$, 1 week, 2 weeks), $100 \mu \mathrm{L}$ of this solution were collected. Briefly, $1 \mu \mathrm{L}$ of internal standard (DTX) at $1 \mathrm{mg} / \mathrm{mL}$ was added and mixed with $200 \mu \mathrm{L}$ of SDS $5 \%$ and then $200 \mu \mathrm{L}$ of dichloromethane. After centrifugation, free PTX was recovered in organic phase, and extraction was repeated twice on the aqueous phase. After evaporation, the solid residue was solubilized in $300 \mu \mathrm{L}$ of mobile phase before HPLC dosing as described above. The extraction yield of PTX is suitable corresponding to $88.5 \pm 2.8 \%(n=4)$. No specific peak of PTX was detected above the limit of quantification (10 nM) up to 2 weeks, revealing the stability of the covalent bond between PTX and nanoparticles in biological conditions.

Cell Culture. 2D Culture. U-87 MG glioblastoma cell line (cancerous), HMEC-1 (noncancerous endothelial cells), and NHDF (noncancerous fibroblasts) were purchased from the American Type Culture Collection (ATCC) and Lonza, respectively. U-87 MG cells were cultured in EMEM with $10 \%$ FBS, $2 \mathrm{mM}$ glutamine, and $1 \%(100 \mathrm{U} / \mathrm{mL})$ penicillin- streptomycin; HMEC-1 cells were cultured in MCDB 131 with $10 \%$ heat-inactivated FBS, $2 \mathrm{mM}$ glutamine, $1 \%$ penicillinstreptomycin, and $10 \mathrm{ng} / \mathrm{mL}$ epidermal growth factor (EGF human protein) and NHDF in fibroblast growth medium supplemented with fibroblast growth kit (Lonza), respectively. U-251 MG glioblastoma cells transfected with dsRed $^{66}$ were kindly provided by Manon Carré and cultured in DMEM with phenol red, $2 \mathrm{mM}$ glutamine, 10\% FBS, and 1\% penicillinstreptomycin. All cells were routinely maintained at $37^{\circ} \mathrm{C}$ and $5 \% \mathrm{CO}_{2}$.

3D Culture. To obtain U-87 MG 3D cell culture in the form of spheroids, cells obtained from the regular $2 \mathrm{D}$ culture were pelleted, resuspended in complete cell culture medium containing $0.25 \%$ of methylcellulose, and placed on a 96 -well round-bottom plate. Cells were seeded at 1000 cells per well in $100 \mu \mathrm{L}$ of medium as described previously. ${ }^{67}$ After $72 \mathrm{~h}$ of growth at $37{ }^{\circ} \mathrm{C}$ under $5 \% \mathrm{CO}_{2}$, spheroids were formed.

Cell Survival Assays. Cell Survival Colorimetric Tests in 2D Culture. Cells (12 500 cells $/ \mathrm{cm}^{2}$ for U-87 MG, 9400 cells/ $\mathrm{cm}^{2}$ for HMEC-1, and 3500 cells $/ \mathrm{cm}^{2}$ for NHDF) were directly seeded in 96-well plates and allowed to grow for $24 \mathrm{~h}$ (U-87 MG and HMEC-1 cells) or $48 \mathrm{~h}$ (NHDF cells) before treatment. Then, adherent cells were treated for $72 \mathrm{~h}$ with a range of concentrations of FONPs $(1,5,25,50,75$, and 100 $\mu \mathrm{g} / \mathrm{mL}$ ) or FONPs-PTX (3.62 to $362 \mu \mathrm{g} / \mathrm{mL}$ of FONPsPTX corresponding to $0.1-10 \mu \mathrm{M}$ PTX-equivalent concentration) dispersed in the respective cell culture media of cells. The number of viable cells was quantified by using three colorimetric assays: MTT assay and resazurin-based (Alamar blue) assay, both based on the metabolic activity of mitochondria, and a protein-biomass-based (sulforhodamine B) assay according to our previous work. ${ }^{68-70}$ All these tests were based on the measurement of absorbance which is proportional to the number of living cells. Cell survival was expressed as a percentage as compared to control cells. At least three independent experiments (in triplicates) were performed, and data were expressed as mean \pm standard deviation.

Real-Time, Label-Free, Impedance-Based Assay. The impedance-meter (xCELLigence, ACEA Biosciences) uses 96-well plates fitted with gold electrodes to monitor variation in impedance of the cell monolayer upon cell proliferation, morphology changes, and attachment of cells (or detachment in the case of cell death). Cells were seeded and treated at exact time points as for colorimetric assays at selected concentrations of FONPs $(5,25,50$, and $100 \mu \mathrm{g} / \mathrm{mL})$. Impedance was measured every $15 \mathrm{~min}$ for 72 additional hours. The percentage of cell viability was obtained by comparing treated samples with respect to the control at the given time point. Each condition was done in quadruplicate. Mean and standard error were calculated from two independent experiments except for NHDF cells for which the experiment was run only once.

Antitumor Activity of FONPS-PTX on 3D Cell Culture. One hundred microliters of complete cell culture medium without methylcellulose (control and negative control), $100 \mu \mathrm{L}$ of FONPs (final concentration in well after dilution 100/200: 181 or $362 \mu \mathrm{g} / \mathrm{mL}$ ), or $100 \mu \mathrm{L}$ of FONPs-PTX (final concentration in well after dilution 100/200: 181 or $362 \mu \mathrm{g} /$ $\mathrm{mL}$ of FONPs-PTX corresponding to 5 or $10 \mu \mathrm{M}$ PTXequivalent concentration) were added to the spheroids. Then, $10 \mu \mathrm{L}$ of complete cell culture medium without methylcellulose were added every $48 \mathrm{~h}$ for 13 days. Spheroid growth was monitored daily by measuring the spheroid area on bright- 
field photomicrographs (Eclipse Ts2-FL, coupled to a digital camera Ds-Fi3, Nikon) with $4 \times$ objective lens. All images were segmented using a custom macro script, written for ImageJ software. Areas of spheroids were normalized to untreated control spheroids. The number of viable cells was quantified by using the fluorometric Alamar blue assay after a 13 day treatment as previously described. ${ }^{67}$ Negative control well values are subtracted to all other wells. The percentage of viable cells was obtained by comparing the fluorescence of treated cells with respect to the control nontreated cells as reference for $100 \%$ viability. The standard deviation was calculated from three independent experiments.

Cellular Internalization. Cell Seeding and Treatment. U87 MG, HMEC-1, NHDF, and U-251 MG cells were seeded for imaging in an eight-well chambered cover glass (Lab-Tek) as for colorimetric assays. After $24 \mathrm{~h}$, cells were treated with FONPs $(1,5$, and $25 \mu \mathrm{g} / \mathrm{mL})$ for $4 \mathrm{~h}$ at $37{ }^{\circ} \mathrm{C}$ and then washed multiple times with PBS, fixed with $4 \%$ paraformaldehyde in PBS (15 min at room temperature), and rinsed twice with PBS. The fixed and washed cells were stored with PBS in the chambers at $4{ }^{\circ} \mathrm{C}$ until observation with a two-photon microscope. For blocking of energy-dependent uptake, cells were incubated with 1 and $5 \mu \mathrm{g} / \mathrm{mL}$ of FONPs for $4 \mathrm{~h}$ at $4{ }^{\circ} \mathrm{C}$ before two photon-microscopy analysis. Inhibition of different endocytosis pathways was assessed by using chlorpromazine (clathrin inhibitor) at $5 \mu \mathrm{g} / \mathrm{mL}$, genistein (caveolin inhibitor) at $200 \mu \mathrm{M}$, or methyl beta cyclodextrin (lipid raft inhibitor) at $1 \mathrm{mM}$. After $30 \mathrm{~min}$ of incubation at $37^{\circ} \mathrm{C}$ with the inhibitor, the cells were washed with cold PBS and incubated with FONPs at 1 and $5 \mu \mathrm{g} / \mathrm{mL}$ during $4 \mathrm{~h}$ at $37^{\circ} \mathrm{C}$. The cells were then rinsed with PBS and fixed for two-photon microscopy.

Two-Photon Microscopy. The cells were imaged using a Zeiss two-photon microscope equipped with a MAI-TAI pulsed laser. Two-photon excitation was performed at $740 \mathrm{~nm}$, and the emission in the 480-550 $\mathrm{nm}$ range was collected using a photomultiplier tube. A dry $20 \times$ objective was used for imaging. The mean intensity and standard deviation of control cells were used to determine the autofluorescence threshold. Autofluorescence contribution in cells treated with FONPs was thresholded with the autofluorescence value of control cells using MATLAB. Only the intensities that were higher by at least one standard deviation from the control mean intensity were plotted in cells treated with FONPs using MATLAB. All these experiments were repeated at least twice.

Immunofluorescence Staining of the Microtubular Network. U-87 MG cells were seeded (10 000 cells per well, $300 \mu \mathrm{L}$ ) on eight-well chamber slides (Lab-Tek). After $24 \mathrm{~h}$, the medium was removed, and the cells were treated with FONPs-PTX (181 or $362 \mu \mathrm{g} / \mathrm{mL}$ of FONPs-PTX corresponding to 5 or $10 \mu \mathrm{M}$ PTX-equivalent concentration in FONPs-PTX) for $24 \mathrm{~h}$. After drug treatment, immunofluorescence staining of the microtubular network was performed using anti- $\beta$-tubulin primary antibody (1:200, mouse monoclonal, Sigma-Aldrich) and FITC-conjugated secondary antibody (1:200, Sigma-Aldrich) as previously described. ${ }^{9}$ To double-label nuclei, cells were further stained with 4,6-diamino-2-phenylindole (DAPI) $(0.25 \mu \mathrm{g} / \mathrm{mL})$. Cells were observed with an epifluorescence microscope (Leica DMIRBE), 40× objective lens, coupled to a digital camera (Coolsnap FX, Princeton Instruments).

Statistical Analysis. Data are presented as mean \pm SEM. Cellular viability data were analyzed by Student's $t$-test. Reported $p$-values are two-sided, and $p<0.05$ was considered statistically significant. Asterisks indicate significant level versus control $* p<0.05 ; * * p<0.01 ; * * * p<0.001$.

\section{ASSOCIATED CONTENT}

\section{Supporting Information}

The Supporting Information is available free of charge on the ACS Publications website at DOI: 10.1021/acsomega.9b02588.

Chemical contents and characteristics of the FONPs; binding energy of the FONPs; photophysical properties of the FONPs in water; distribution of the height of FONPs measured by AFM; ${ }^{1} \mathrm{H}$ NMR spectra of the FONPs; oxygen and nitrogen XPS spectra of FONPs; Raman spectrum of the FONPs; evolution of the FONP fluorescence in varying conditions; two-photon fluorescence images of cells incubated with FONPs; and HPLC calibration curve of PTX (PDF)

\section{AUTHOR INFORMATION}

\section{Corresponding Authors}

*E-mail: mireille.blanchard-desce@u-bordeaux.fr (M.B.-D.).

*E-mail: marie-anne.esteve@univ-amu.fr (M.-A.E.).

ORCID ${ }^{\circ}$

Sounderya Nagarajan: 0000-0002-9440-1379

Noé Dumas: 0000-0001-5665-8096

Mireille Blanchard-Desce: 0000-0002-1572-9545

Marie-Anne Estève: 0000-0001-8178-3606

Author Contributions

${ }$ M.M. and S.N. contributed equally to this work.

Notes

The authors declare no competing financial interest.

\section{ACKNOWLEDGMENTS}

This work has been carried out within the framework of the Cancer Plan thanks to the financial support from ITMO Cancer AVIESAN (Alliance Nationale pour les Sciences de la Vie et de la Santé, National Alliance for Life Sciences \& Health) of "LASERNANOCANCER" (no. PC201420) project. We also acknowledge the support from the French State, managed by the French National Research Agency (ANR) in the frame of the "Investments for the future" Programme IdEx Bordeaux-LAPHIA (ANR-10-IDEX-03-02), and from the PACA Canceropôle and INCa in "NanoTax" project (no. 2018-08). TEM was performed at the Bordeaux Imaging Center (UMS 3420 CNRS-University of Bordeaux/Inserm US4), while two-photon imaging was performed on PiCSL-FBI core facility (IBDM, AMU-Marseille), both being members of France Bioimaging, an infrastructure supported by the ANR (ANR-10-INSB-04, "Investments for the future"). The help of Sabrina Lacomme and Melina Petrel (TEM) and Florence Chaspoul (HPLC dosing) is acknowledged.

\section{REFERENCES}

(1) Jain, V.; Jain, S.; Mahajan, S. C. Nanomedicines Based Drug Delivery Systems for Anti-Cancer Targeting and Treatment. Curr. Drug Deliv. 2015, 12, 177-191.

(2) Sun, T.; Zhang, Y. S.; Pang, B.; Hyun, D. C.; Yang, M.; Xia, Y. Engineered Nanoparticles for Drug Delivery in Cancer Therapy. Angew. Chem. Int. Ed. Engl. 2014, 53, 12320-12364.

(3) Pérez-Herrero, E.; Fernández-Medarde, A. Advanced Targeted Therapies in Cancer: Drug Nanocarriers, the Future of Chemotherapy. Eur. J. Pharm. Biopharm. 2015, 93, 52-79. 
(4) Nabil, G.; Bhise, K.; Sau, S.; Atef, M.; El-Banna, H. A.; Iyer, A. K. Nano-Engineered Delivery Systems for Cancer Imaging and Therapy: Recent Advances, Future Direction and Patent Evaluation. Drug Discov. Today 2019, 24, 462-491.

(5) Kim, S.-W.; Lee, Y. K.; Kim, S.-H.; Park, J.-Y.; Lee, D. U.; Choi, J.; Hong, J. H.; Kim, S.; Khang, D. Covalent, Non-Covalent, Encapsulated Nanodrug Regulate the Fate of Intra- and Extracellular Trafficking: Impact on Cancer and Normal Cells. Sci. Rep. 2017, 7, 6454.

(6) Gingras, M.; Raimundo, J.-M.; Chabre, Y. M. Cleavable Dendrimers. Angew. Chem., Int. Ed. Engl. 2007, 46, 1010-1017.

(7) Yang, D.; Van, S.; Liu, J.; Wang, J.; Jiang, X.; Wang, Y.; Yu, L. Physicochemical Properties and Biocompatibility of a PolymerPaclitaxel Conjugate for Cancer Treatment. Int. J. Nanomed. 2011, 6, 2557-2566.

(8) Zhang, S.; Zou, J.; Elsabahy, M.; Karwa, A.; Li, A.; Moore, D. A.; Dorshow, R. B.; Wooley, K. L. Poly(Ethylene Oxide)-BlockPolyphosphester-Based Paclitaxel Conjugates as a Platform for Ultra-High Paclitaxel-Loaded Multifunctional Nanoparticles. Chem. Sci. 2013, 4, 2122-2126.

(9) Correard, F.; Roy, M.; Terrasson, V.; Braguer, D.; Estève, M. A.; Gingras, M. Delaying Anticancer Drug Delivery by Self-Assembly and Branching Effects of Minimalist Dendron-Drug Conjugates. Chemistry 2019, 25, 9586-9591.

(10) Wang, F.; Porter, M.; Konstantopoulos, A.; Zhang, P.; Cui, H. Preclinical Development of Drug Delivery Systems for PaclitaxelBased Cancer Chemotherapy. J. Control. Release 2017, 267, 100-118.

(11) Jordan, M. A.; Wilson, L. Microtubules as a Target for Anticancer Drugs. Nat. Rev. Cancer 2004, 4, 253-265.

(12) Gelderblom, H.; Verweij, J.; Nooter, K.; Sparreboom, A. Cremophor EL. Eur. J. Cancer 2001, 37, 1590-1598.

(13) Yusuf, R.; Duan, Z.; Lamendola, D.; Penson, R.; Seiden, M. Paclitaxel Resistance: Molecular Mechanisms and Pharmacologic Manipulation. Curr. Cancer Drug Targets 2003, 3, 1-19.

(14) Cardoso, F. L.; Brites, D.; Brito, M. A. Looking at the BloodBrain Barrier: Molecular Anatomy and Possible Investigation Approaches. Brain Res. Rev. 2010, 64, 328-363.

(15) Sofias, A. M.; Dunne, M.; Storm, G.; Allen, C. The Battle of "Nano" Paclitaxel. Adv. Drug Deliv. Rev. 2017, 122, 20-30.

(16) Azad, T. D.; Pan, J.; Connolly, I. D.; Remington, A.; Wilson, C. M.; Grant, G. A. Therapeutic Strategies to Improve Drug Delivery across the Blood-Brain Barrier. Neurosurg. Focus 2015, 38, No. E9.

(17) Stupp, R.; Mason, W. P.; van den Bent, M. J.; Weller, M.; Fisher, B.; Taphoorn, M. J. B.; Belanger, K.; Brandes, A. A.; Marosi, C.; Bogdahn, U.; et al. Radiotherapy plus Concomitant and Adjuvant Temozolomide for Glioblastoma. N. Engl. J. Med. 2005, 352, 987996.

(18) Garg, T.; Bhandari, S.; Rath, G.; Goyal, A. K. Current Strategies for Targeted Delivery of Bio-Active Drug Molecules in the Treatment of Brain Tumor. J. Drug Target. 2015, 23, 865-887.

(19) Pinto, M. P.; Arce, M.; Yameen, B.; Vilos, C. Targeted Brain Delivery Nanoparticles for Malignant Gliomas. Nanomedicine 2017, $12,59-72$.

(20) Jeyapalan, S.; Boxerman, J.; Donahue, J.; Goldman, M.; Kinsella, T.; Dipetrillo, T.; Evans, D.; Elinzano, H.; Constantinou, M.; Stopa, E.; et al. Paclitaxel Poliglumex, Temozolomide, and Radiation for Newly Diagnosed High-Grade Glioma: A Brown University Oncology Group Study. Am. J. Clin. Oncol. 2014, 37, 444-449.

(21) Elinzano, H.; Glantz, M.; Mrugala, M.; Kesari, S.; Piccioni, D. E.; Kim, L.; Pan, E.; Yunus, S.; Coyle, T.; Timothy, K.; et al. PPX and Concurrent Radiation for Newly Diagnosed Glioblastoma Without MGMT Methylation: A Randomized Phase II Study: BrUOG 244. Am. J. Clin. Oncol. 2018, 41, 159-162.

(22) Ke, X.-Y.; Zhao, B.-J.; Zhao, X.; Wang, Y.; Huang, Y.; Chen, X.M.; Zhao, B.-X.; Zhao, S.-S.; Zhang, X.; Zhang, Q. The Therapeutic Efficacy of Conjugated Linoleic Acid - Paclitaxel on Glioma in the Rat. Biomaterials 2010, 31, 5855-5864.

(23) Li, D.; Yang, K.; Li, J.-S.; Ke, X.-Y.; Duan, Y.; Du, R.; Song, P.; Yu, K.-F.; Ren, W.; Huang, D.; et al. Antitumor Efficacy of a Novel
CLA-PTX Microemulsion against Brain Tumors: In Vitro and in Vivo Findings. Int. J. Nanomed. 2012, 7, 6105-6114.

(24) Wang, J.; Liu, W.; Tu, Q.; Wang, J.; Song, N.; Zhang, Y.; Nie, N.; Wang, J. Folate-Decorated Hybrid Polymeric Nanoparticles for Chemically and Physically Combined Paclitaxel Loading and Targeted Delivery. Biomacromolecules 2011, 12, 228-234.

(25) Jiang, Y.; Wang, X.; Liu, X.; Lv, W.; Zhang, H.; Zhang, M.; Li, X.; Xin, H.; Xu, Q. Enhanced Antiglioma Efficacy of Ultrahigh Loading Capacity Paclitaxel Prodrug Conjugate Self-Assembled Targeted Nanoparticles. ACS Appl. Mater. Interfaces 2017, 9, 211217.

(26) Eldar-Boock, A.; Miller, K.; Sanchis, J.; Lupu, R.; Vicent, M. J.; Satchi-Fainaro, R. Integrin-Assisted Drug Delivery of Nano-Scaled Polymer Therapeutics Bearing Paclitaxel. Biomaterials 2011, 32, $3862-3874$.

(27) Wang, Y.; Hu, A. Carbon Quantum Dots: Synthesis, Properties and Applications. J. Mater. Chem. C 2014, 2, 6921-6939.

(28) So, R. C.; Sanggo, J. E.; Jin, L.; Diaz, J. M. A.; Guerrero, R. A.; $\mathrm{He}$, J. Gram-Scale Synthesis and Kinetic Study of Bright Carbon Dots from Citric Acid and Citrus Japonica via a Microwave-Assisted Method. ACS Omega 2017, 2, 5196-5208.

(29) Cayuela, A.; Soriano, M. L.; Carrillo-Carrión, C.; Valcárcel, M. Semiconductor and Carbon-Based Fluorescent Nanodots: The Need for Consistency. Chem. Commun. 2016, 52, 1311-1326.

(30) Zhang, M.; Hu, L.; Wang, H.; Song, Y.; Liu, Y.; Li, H.; Shao, M.; Huang, H.; Kang, Z. One-Step Hydrothermal Synthesis of Chiral Carbon Dots and Their Effects on Mung Bean Plant Growth. Nanoscale 2018, 10, 12734-12742.

(31) Sciortino, A.; Marino, E.; van Dam, B.; Schall, P.; Cannas, M.; Messina, F. Solvatochromism Unravels the Emission Mechanism of Carbon Nanodots. J. Phys. Chem. Lett. 2016, 7, 3419-3423.

(32) Shangguan, J.; He, D.; He, X.; Wang, K.; Xu, F.; Liu, J.; Tang, J.; Yang, X.; Huang, J. Label-Free Carbon-Dots-Based Ratiometric Fluorescence $\mathrm{PH}$ Nanoprobes for Intracellular $\mathrm{PH}$ Sensing. Anal. Chem. 2016, 88, 7837-7843.

(33) Zhang, J.; Yu, S.-H. Carbon Dots: Large-Scale Synthesis, Sensing and Bioimaging. Mater. Today 2016, 19, 382-393.

(34) Zhu, S.; Song, Y.; Zhao, X.; Shao, J.; Zhang, J.; Yang, B. The Photoluminescence Mechanism in Carbon Dots (Graphene Quantum Dots, Carbon Nanodots, and Polymer Dots): Current State and Future Perspective. Nano Res. 2015, 8, 355-381.

(35) Song, Y.; Zhu, S.; Zhang, S.; Fu, Y.; Wang, L.; Zhao, X.; Yang, B. Investigation from Chemical Structure to Photoluminescent Mechanism: A Type of Carbon Dots from the Pyrolysis of Citric Acid and an Amine. J. Mater. Chem. C 2015, 3, 5976-5984.

(36) Zhu, S.; Zhao, X.; Song, Y.; Lu, S.; Yang, B. Beyond Bottom-up Carbon Nanodots: Citric-Acid Derived Organic Molecules. Nano Today 2016, 11, 128-132.

(37) Kasprzyk, W.; Bednarz, S.; Żmudzki, P.; Galica, M.; Bogdal, D. Novel Efficient Fluorophores Synthesized from Citric Acid. RSC Adv. 2015, 5, 34795-34799.

(38) Xu, Y.; Wu, M.; Liu, Y.; Feng, X.-Z.; Yin, X.-B.; He, X.-W.; Zhang, Y.-K. Nitrogen-Doped Carbon Dots: A Facile and General Preparation Method, Photoluminescence Investigation, and Imaging Applications. Chemistry 2013, 19, 2276-2283.

(39) Krysmann, M. J.; Kelarakis, A.; Dallas, P.; Giannelis, E. P. Formation Mechanism of Carbogenic Nanoparticles with Dual Photoluminescence Emission. J. Am. Chem. Soc. 2012, 134, 747-750.

(40) Song, Y.; Zhu, S.; Yang, B. Bioimaging Based on Fluorescent Carbon Dots. RSC Adv. 2014, 4, 27184-27200.

(41) Schneider, J.; Reckmeier, C. J.; Xiong, Y.; von Seckendorff, M.; Susha, A. S.; Kasák, P.; Rogach, A. L. Molecular Fluorescence in Citric Acid-Based Carbon Dots. J. Phys. Chem. C 2017, 121, 2014-2022.

(42) Sun, Y.-P.; Zhou, B.; Lin, Y.; Wang, W.; Fernando, K. A. S.; Pathak, P.; Meziani, M. J.; Harruff, B. A.; Wang, X.; Wang, H.; et al. Quantum-Sized Carbon Dots for Bright and Colorful Photoluminescence. J. Am. Chem. Soc. 2006, 128, 7756-7757. 
(43) Chakrabarti, M.; Kiseleva, R.; Vertegel, A.; Ray, S. K. Carbon Nanomaterials for Drug Delivery and Cancer Therapy. J. Nanosci. Nanotechnol. 2015, 15, 5501-5511.

(44) Ruan, S.; Qian, J.; Shen, S.; Zhu, J.; Jiang, X.; He, Q.; Gao, H. A Simple One-Step Method to Prepare Fluorescent Carbon Dots and Their Potential Application in Non-Invasive Glioma Imaging. Nanoscale 2014, 6, 10040-10047.

(45) Zakrzewska, K. E.; Samluk, A.; Wierzbicki, M.; Jaworski, S.; Kutwin, M.; Sawosz, E.; Chwalibog, A.; Pijanowska, D. G.; Pluta, K. D. Analysis of the Cytotoxicity of Carbon-Based Nanoparticles, Diamond and Graphite, in Human Glioblastoma and Hepatoma Cell Lines. PLoS One 2015, 10, No. e0122579.

(46) Ostadhossein, F.; Pan, D. Functional Carbon Nanodots for Multiscale Imaging and Therapy. Wiley Interdiscip. Rev.: Nanomed. Nanobiotechnol. 2017, 9, No. e1436.

(47) Lee, C.; Kwon, W.; Beack, S.; Lee, D.; Park, Y.; Kim, H.; Hahn, S. K.; Rhee, S.-W.; Kim, C. Biodegradable Nitrogen-Doped Carbon Nanodots for Non-Invasive Photoacoustic Imaging and Photothermal Therapy. Theranostics 2016, 6, 2196-2208.

(48) Wu, Y.-F.; Wu, H.-C.; Kuan, C.-H.; Lin, C.-J.; Wang, L.-W.; Chang, C.-W.; Wang, T.-W. Multi-Functionalized Carbon Dots as Theranostic Nanoagent for Gene Delivery in Lung Cancer Therapy. Sci. Rep. 2016, 6, 21170.

(49) Zheng, M.; Ruan, S.; Liu, S.; Sun, T.; Qu, D.; Zhao, H.; Xie, Z.; Gao, H.; Jing, X.; Sun, Z. Self-Targeting Fluorescent Carbon Dots for Diagnosis of Brain Cancer Cells. ACS Nano 2015, 9, 11455-11461.

(50) Ong, K. J.; MacCormack, T. J.; Clark, R. J.; Ede, J. D.; Ortega, V. A.; Felix, L. C.; Dang, M. K. M.; Ma, G.; Fenniri, H.; Veinot, J. G. C.; et al. Widespread Nanoparticle-Assay Interference: Implications for Nanotoxicity Testing. PLoS One 2014, 9, No. e90650.

(51) Wang, J.; Liu, J. PEI-Folic Acid Modified Carbon Nanodots for Cancer Cell-Targeted Delivery and Two-Photon Excitation Imaging. RSC Adv. 2016, 6, 19662-19668.

(52) Lan, M.; Zhao, S.; Zhang, Z.; Yan, L.; Guo, L.; Niu, G.; Zhang, J.; Zhao, J.; Zhang, H.; Wang, P.; et al. Two-Photon-Excited nearInfrared Emissive Carbon Dots as Multifunctional Agents for Fluorescence Imaging and Photothermal Therapy. Nano Res. 2017, $10,3113-3123$.

(53) Wang, J.; Zhang, Z.; Zha, S.; Zhu, Y.; Wu, P.; Ehrenberg, B.; Chen, J.-Y. Carbon Nanodots Featuring Efficient FRET for TwoPhoton Photodynamic Cancer Therapy with a Low Fs Laser Power Density. Biomaterials 2014, 35, 9372-9381.

(54) Tang, J.; Kong, B.; Wu, H.; Xu, M.; Wang, Y.; Wang, Y.; Zhao, D.; Zheng, G. Carbon Nanodots Featuring Efficient FRET for RealTime Monitoring of Drug Delivery and Two-Photon Imaging. Adv. Mater. 2013, 25, 6569-6574.

(55) Lin, T.; Zhao, P.; Jiang, Y.; Tang, Y.; Jin, H.; Pan, Z.; He, H.; Yang, V. C.; Huang, Y. Blood-Brain-Barrier-Penetrating Albumin Nanoparticles for Biomimetic Drug Delivery via Albumin-Binding Protein Pathways for Antiglioma Therapy. ACS Nano 2016, 10, 9999-10012.

(56) Cheng, X.; Tian, X.; Wu, A.; Li, J.; Tian, J.; Chong, Y.; Chai, Z.; Zhao, Y.; Chen, C.; Ge, C. Protein Corona Influences Cellular Uptake of Gold Nanoparticles by Phagocytic and Nonphagocytic Cells in a Size-Dependent Manner. ACS Appl. Mater. Interfaces 2015, 7, 2056820575.

(57) Kingston, D. G. I. Taxol: The Chemistry and Structure-Activity Relationships of a Novel Anticancer Agent. Trends Biotechnol. 1994, 12, 222-227.

(58) Xia, X. J.; Peng, J.; Zhang, P. X.; Jin, D. J.; Liu, Y. L. Validated HPLC Method for the Determination of Paclitaxel-Related Substances in an Intravenous Emulsion Loaded with a PaclitaxelCholesterol Complex. Indian J. Pharm. Sci. 2013, 75, 672-679.

(59) Gomez, I. J.; Arnaiz, B.; Cacioppo, M.; Arcudi, F.; Prato, M. Nitrogen-Doped Carbon Nanodots for Bioimaging and Delivery of Paclitaxel. J. Mater. Chem. B 2018, 6, 5540-5548.

(60) Pagano, A.; Sté, N. A.; Honoré, p.; Estè, M. A.; ve, N. A.; Braguer, D. Nanodrug Potential in Cancer Therapy: Efficacy/Toxicity Studies in Cancer Cells. Int. J. Nanotechnol. 2012, 9, 502-516.
(61) Leong, D. T.; Ng, K. W. Probing the Relevance of 3D Cancer Models in Nanomedicine Research. Adv. Drug Deliv. Rev. 2014, 7980, 95-106.

(62) Wang, D.-D.; Liu, W.; Chang, J.-J.; Cheng, X.; Zhang, X.-Z.; Xu, H.; Feng, D.; Yu, L.-J.; Wang, X.-L. Bioengineering Three-Dimensional Culture Model of Human Lung Cancer Cells: An Improved Tool for Screening EGFR Targeted Inhibitors. RSC Adv. 2016, 6, 24083-24090.

(63) Xu, C.; Webb, W. W. Measurement of Two-Photon Excitation Cross Sections of Molecular Fluorophores with Data from 690 to 1050 Nm. J. Opt. Soc. Am. B 1996, 13, 481-491.

(64) Albota, M. A.; Xu, C.; Webb, W. W. Two-Photon Fluorescence Excitation Cross Sections of Biomolecular Probes from 690 to 960 Nm. Appl. Opt. 1998, 37, 7352-7356.

(65) Werts, M. H. V.; Nerambourg, N.; Pélégry, D.; Grand, Y. L.; Blanchard-Desce, M. Action Cross Sections of Two-Photon Excited Luminescence of Some $\mathrm{Eu}(\mathrm{III})$ and $\mathrm{Tb}(\mathrm{III})$ Complexes. Photochem. Photobiol. Sci. 2005, 4, 531-538.

(66) Alves, I. D.; Carré, M.; Montero, M.-P.; Castano, S.; Lecomte, S.; Marquant, R.; Lecorché, P.; Burlina, F.; Schatz, C.; Sagan, S.; et al. A Proapoptotic Peptide Conjugated to Penetratin Selectively Inhibits Tumor Cell Growth. Biochim. Biophys. Acta 2014, 1838, 2087-2098.

(67) Berges, R.; Denicolai, E.; Tchoghandjian, A.; Baeza-Kallee, N.; Honore, S.; Figarella-Branger, D.; Braguer, D. Proscillaridin A Exerts Anti-Tumor Effects through GSK3 $\beta$ Activation and Alteration of Microtubule Dynamics in Glioblastoma. Cell Death Dis. 2018, 9, 984.

(68) Correard, F.; Maximova, K.; Estève, M.-A.; Villard, C.; Roy, M.; Al-Kattan, A.; Sentis, M.; Gingras, M.; Kabashin, A. V.; Braguer, D. Gold Nanoparticles Prepared by Laser Ablation in Aqueous Biocompatible Solutions: Assessment of Safety and Biological Identity for Nanomedicine Applications. Int. J. Nanomed. 2014, 9, 5415-5430.

(69) Pasquier, E.; Tuset, M.-P.; Street, J.; Sinnappan, S.; MacKenzie, K. L.; Braguer, D.; Andre, N.; Kavallaris, M. Concentration- and Schedule-Dependent Effects of Chemotherapy on the Angiogenic Potential and Drug Sensitivity of Vascular Endothelial Cells. Angiogenesis 2013, 16, 373-386.

(70) Berges, R.; Tchoghandjian, A.; Honore, S.; Esteve, M.-A.; Figarella-Branger, D.; Bachmann, F.; Lane, H. A.; Braguer, D. The Novel Tubulin-Binding Checkpoint Activator BAL101553 Inhibits EB1-Dependent Migration and Invasion and Promotes Differentiation of Glioblastoma Stem-like Cells. Mol. Cancer Ther. 2016, 15, 27402749. 